\title{
Exosome release and neuropathology induced by a-synuclein: new insights into protective mechanisms of Drp1 inhibition
}

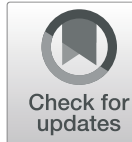

\author{
Rebecca Z. Fan ${ }^{1,2}$, Min Guo $^{1,3}$, Shouqing Luo ${ }^{2}$, Mei Cui ${ }^{3 *}$ and Kim Tieu ${ }^{1 *}$ (D)
}

\begin{abstract}
Targeting alpha-synuclein (a-syn) as a therapeutic strategy for Parkinson's disease (PD) has been intensively pursued largely due to its well-recognized pathogenic role. Since its discovery as the first familial link to PD over two decades ago, this protein has been associated with multiple neurotoxic mechanisms, such as mitochondrial dysfunction and impaired autophagic flux. We report here that blocking dynamin-related protein 1 (Drp1) improved both mitochondrial function and autophagic flux in experimental models of a-syn. Using rat dopaminergic neuronal cells with inducible wild-type human a-syn, we observed excessive mitochondrial fragmentation and increased Drp1 levels $48 \mathrm{~h}$ after gene induction. Functionally, these cells exhibited lower mitochondrial membrane potential, reduced ATP production rate and mitochondrial spare respiratory capacity, as well as increased levels of mitochondrial reactive oxygen species. To evaluate the protective role of Drp1 inhibition, we used three complementary approaches: gene silencing mediated by siRNA, overexpression of Drp1-dominant negative and the small molecule mitochondrial division inhibitor-1 (mdivi-1). Both morphological and functional defects induced by a-syn were attenuated by these strategies. Importantly, Drp1 inhibition reduced proteinase K-resistant a-syn aggregates. Based on that observation, we investigated the involvement of autophagy. Through a combination of stable autophagy reporter cells and immunoreactivity for LC3 and p62 in neuronal cells with either a-syn overexpression or treatment of human a-syn preformed fibrils (PFF), we observed that Drp1 inhibition abolished autophagic impairment induced by a-syn. Consistent with its role in improving autophagy function, Drp1 inhibition reduced exosome release and spread of a-syn pathology from neurons to neurons and from microglia to neurons. In summary, this study highlights new insights that Drp1 inhibition confers neuroprotection through both mitochondrial and autophagy-lysosomal pathways, further strengthening the therapeutic potential of targeting Drp1.
\end{abstract}

Keywords: Parkinson's disease, Mitochondrial dynamics, Neurodegeneration, Alpha-synuclein, Autophagy, Protein aggregation

\section{Introduction}

Parkinson's disease (PD) is a complex and multifactorial disorder involving both genetic mutations and environmental factors [28]. Since the identification of the first mutation in SNCA [50], the gene encoding $\alpha$-synuclein $(\alpha-$-syn), the list of additional mutations linked to PD has expanded rapidly and become rather complex $[28,29,53]$. To date, the most investigated PD-linked gene is SNCA.

\footnotetext{
* Correspondence: cuimei@fudan.edu.cn; ktieu@fiu.edu

${ }^{3}$ Department of Neurology, Huashan hospital, Fudan University, Shanghai, China

'Department of Environmental Health Sciences, Florida International University, Miami, USA

Full list of author information is available at the end of the article
}

Missense mutations as well as gene duplications and triplications of SNCA have been identified in familial PD [3, 34, 38, 50, 61, 73]. The discovery of increasing the gene dosage of SNCA by two to three fold can also cause PD [61] signifies that elevated wild-type (WT) $\alpha$-syn alone is sufficient to cause the disease. $\alpha$-syn is prominently present in Lewy bodies, which are intra-neuronal proteins aggregates commonly observed in PD [64]. Although mutation in this gene is rare, the SNCA locus has been demonstrated to have genome-wide significant association with PD development [39]. Genome-wide association studies (GWAS) have identified $S N C A$ as a major gene associated with sporadic PD [26, 46, 59]. The fact

(c) The Author(s). 2019 Open Access This article is distributed under the terms of the Creative Commons Attribution 4.0 International License (http://creativecommons.org/licenses/by/4.0/), which permits unrestricted use, distribution, and 
that $\alpha$-syn is involved in both familial and sporadic PD makes it a significant and attractive protein to investigate pathogenic mechanisms and therapeutic target for this neurological disorder. Neurotoxic mechanisms associated with $\alpha$-syn have therefore been at the forefront of the PD research and have greatly contributed to the current understanding of the disease pathology.

$\alpha$-syn has been demonstrated to induce neurotoxicity through multiple but non-mutually exclusive mechanisms $[7,17,22,28]$, including impairment in mitochondrial and autophagy-lysosomal function resulting in protein aggregation, mitochondrial impairment, oxidative stress and exosome release - all of which are the topics of interest in the present study. Relevant to this study we recently published data demonstrating that by using the small molecule Mitochondrial Division Inhibitor-1 (mdivi-1), a putative inhibitor of the mitochondrial fission DynamicRelated Protein-1 (Drp1), we were able to reduce neuropathology induced by $\alpha$-syn-A53T in rats [4]. However, some critical questions remained from that study. First, mdivi-1 was used to block Drp1 function [4]. Although this inhibitor has been widely reported to produce effects consistent with blocking mitochondrial fission and GTPase function of Drp1 [42, 63], questions have been raised whether this inhibitor blocks Drp1 function [6]. Second, $\alpha-$ syn-A53T mutation was used to model PD. Given that this missense mutation is rare and responsible for a very small fraction of PD cases, the significance of that study in relation to sporadic PD needs to be validated in models with wild-type (WT) human $\alpha$-syn. Third, to date, Drp1 is commonly referred to as a "mitochondrial fission" protein. However, most of Drp1 resides, not on mitochondria, but elsewhere in the cell. Indeed, a previous study estimated that only about $3 \%$ of Drp1 is localized to mitochondria under normal physiological condition [62]. Although under pathological condition, post-translational modifications such as phosphorylation of Drp1 at S616, would induce its translocation to mitochondria, a significant portion most likely still remains in the cytosol. It is critical to investigate additional protective mechanisms of this protein. The present study addresses these three issues and we report here that blocking Drp1 genetically improved neuropathological hallmarks associated with mitochondrial dysfunction and autophagy flux impairment induced by human $\alpha$-synWT. Consistent with these mechanisms, we observed improved mitochondrial function as well as reduced $\alpha$-syn aggregation and exosome release when Drp1 was inhibited.

\section{Materials and methods Cell cultures}

Generation of stable and inducible human wild-type asynuclein in dopaminergic neuronal cells

Stable cells with inducible $\alpha$-syn-WT expression were generated by stably transfecting the rat dopaminergic neuronal cells N27 (1RB3A) [51, 52] (provided by Dr. Anumantha Kanthasamy, Iowa State University) with an ecdysone inducible system, the Complete Control Inducible Mammalian Expression System (Stratagene), as we previously described in details for the PINK1 models [15]. The cDNA of full length human wild-type SNCA was subcloned into the multiple cloning site. Stably transformed cells were selected and maintained in RPMI containing $10 \%$ FBS, G418 $(500 \mu \mathrm{g} / \mathrm{ml})$ and hygromycin $(200 \mu \mathrm{g} / \mathrm{ml})$. Of note, due to the potential concern that N27 cells in some laboratories have a mixed population because of extensive passaging over time, we performed immunocytochemistry and immunoblotting and confirmed that approximately $91 \%$ of our N27 cells have tyrosine hydroxylase (a dopaminergic marker) immunoreactivity (Additional file 1: Figure S1). Quantification was performed by counting DAPI with or without TH immunoreactivity.

Our initial attempt was to select inducible cells with high expression of GFP using flow cytometry. However, due to undetectable GFP intensity (which could occur for a protein expressed downstream of IRES) [43], we directly selected cells with high expression of $\alpha$-syn using SMARTFLARE human SNCA-Cy3 mRNA probe (Millipore, SF-1254). This non-toxic probe was taken up by living cells through endocytosis. Once inside the cell, it recognizes and binds to human $\alpha$-syn mRNA, resulting in fluorescent signal. For sorting, cells were treated with $20 \mu \mathrm{M}$ PonA (or ethanol vehicle control) for $24 \mathrm{~h}$ and SMARTFLARE probe (200 $\mathrm{nM}$ ) was added $\sim 16 \mathrm{~h}$ prior to sorting using FACSAria II. Cells were maintained in RPMI 1640 containing10\% FBS, G418 $(500 \mu \mathrm{g} / \mathrm{ml})$ and hygromycin B $(200 \mu \mathrm{g} / \mathrm{ml})$ (complete medium). The expression of $\alpha$ syn upon PonA induction was confirmed using immunostaining and western blot.

\section{Stable autophagy reporter HeLa cells}

HeLa cells with stable overexpression of mRFP-GFPLC3 were designed to monitor autophagy flux as previously described [32]. We have successfully used these cells to measure autophagy flux $[9,10]$. These cells were maintained in DMEM + 10\%FBS + G418 $(100 \mu \mathrm{g} / \mathrm{ml})+$ $1 \%$ penicillin/streptomycin. Of note, because we needed to performed immunostaining to identify cell with $\alpha$-syn overexpression, we chose to use fixed cells instead of live cell imaging in this study. Due to the potential concern that fixation may bring back the quenched GFP signal, we directly compared the signal intensity of cells with or without PFA fixation. As seen below Additional file 1: Figure S2, GFP signal was not affected by fixation; otherwise, every single cell would have had a green signal indicating autophagy flux is functional and the GFP signal is quenched when autophagosomes fuse with the acidic environment of the lysosomes. 


\section{Microglia}

Primary cultured mouse microglia were prepared from post-natal day 0 (P0) newborn C57BL/6 pups as described [21]. Briefly, meninges-free cortices were isolated and trypsinized. Cells were cultured in complete DMEM-F12 with 10\% FBS and penicillin/streptomycin. Murine monocyte colony stimulating factor (M-CSF, $10 \mathrm{ng} / \mathrm{ml}$, cat. no.315-02, Peprotech, CA) was added to the medium 6 days after plating. After 15 days, the cultures were shaken ( $4 \mathrm{~h} ; 260 \mathrm{rpm}$ on a rotary shaker) to remove microglia.

\section{SH-SY5Y cells and BV2 cells}

Human neuroblastoma SH-SY5Y and immortalized mouse microglia BV-2 cells were cultured in DMEM containing 10\% FBS, penicillin G and streptomycin sulfate.

\section{siRNA-mediated Drp1 knockdown}

Pre-designed siRNA against rat dnm1l and human DNM1L (gene encoding Drp1) were purchased from Dharmacon Research, Inc. SMARTpool: siGENOME Rat Dnm1l siRNA was used for the N27 cells and SMARTpool: siGENOME Human Dnm1l siRNA was for HeLa cells. Each of this product is a mixture of four individual siRNA duplexes that target four separate sequences of the gene to maximize efficiency of gene silencing. To enhance transfection efficiency, an "in-tube" transfection procedure [15] was used with the following modifications: Cell suspension $(80,000-100,000$ cells $/ \mathrm{ml})$ were mixed with jetPRIME $^{\text {Tix }}$ DNA and siRNA Transfection Reagent (Polyplustransfection ${ }^{\circ} \mathrm{SA}$ ). For every $500 \mu \mathrm{L}$ of cell suspension (RPMI $+10 \% \mathrm{FBS}), 50 \mu \mathrm{L}$ of JetPRIME buffer and $2 \mu \mathrm{L}$ JetPRIME reagent were used. Cells were plated and left in transfection medium overnight, then media was changed the following day. Gene silencing efficiency was confirmed using western blot, with $10 \mathrm{nM}$ of siRNA achieving 75-90\% knockdown compared to scrambled control (siGENOME NonTargeting siRNA Control Pools, Cat\# D-001206, Dharmacon Inc) after $48 \mathrm{~h}$.

\section{Preparation of human a-syn pre-formed fibrils (PFF)}

$\alpha$-syn monomers were obtained from the Michael J. Fox Foundation and the generation of PFF was performed according to the accompanying protocol (https://www. michaeljfox.org/files/accelerate/models/PFF\%20Protocol \%202017b.pdf). Briefly, the frozen aliquot was thawed on ice, centrifuged at $15,000 \times g$ for $10 \mathrm{~min}$ at $4{ }^{\circ} \mathrm{C}$ with a SORVALL legend micro 21R centrifuge (Thermo Scientific). Protein concentration was determined using BCA assay (Thermo Scientific Pierce) and the samples were diluted in sterile PBS to $5 \mathrm{mg} / \mathrm{ml}$ in a $1.5 \mathrm{ml}$ Eppendorf protein low-bind tube. The sample was quickly centrifuged and placed in an Eppendorf ThermoMixer C orbital shaker (with thermo top on), shaken at $1000 \mathrm{RPM}$ for seven consecutive days at $37^{\circ} \mathrm{C}$. The stock samples were aliquoted and stored at $-80^{\circ} \mathrm{C}$. To assess morphology of PFF, transmission electron microscopy (TEM, Phillip CM120) was used. To this end, the recombinant protein was diluted into $1 \mathrm{mg} / \mathrm{ml}$ in dPBS and sonicated using either QSonica XL-2000 at power level 2 for a total of 30 pulses ( $1 \mathrm{~s}$ each) or Fisher Scientific 120 Sonic Dismembrator equipped with CL-18 microtip (20\% power) and then transferred to carbon-coated 200-mesh copper electron microscopy grids separately. Subsequently, PFF was negatively stained with $1 \%$ uranium acetate and its morphology was identified by TEM.

\section{PFF treatment in cell cultures}

The frozen aliquot of $\alpha$-syn as described above was thawed at room temperature, diluted to $0.1 \mathrm{mg} / \mathrm{ml}$ using sterile dPBS (volume 200-400 $\mu \mathrm{l}$ ), and sonicated as described above. The sonicated solution was diluted to working concentrations in cell culture media prior to being used for the following experiments:

1) $S H-S Y 5 Y$ and $B V-2$ cells were transfected with siRNA-Drp1(50 nM) or scramble control for $12 \mathrm{~h}$, followed by PFF $(2 \mu \mathrm{g} / \mathrm{ml})$ treatment for $24 \mathrm{~h}$, and cultured for additional $36 \mathrm{~h}$ after PFF withdrawal. For mdivi-1 treatment, PFF was added concurrently with mdivi-1 $(20 \mu \mathrm{M})$. Conditional media $(\mathrm{CM})$ were then collected for exosome isolation.

2) Mouse primary microglia were treated with PFF for $24 \mathrm{~h}$ in the presence or absence of mdivi-1, and further cultured for $36 \mathrm{~h}$ after PFF withdrawal. To activate microglia, cells were treated with LPS $(1 \mu \mathrm{g} / \mathrm{ml})$ for $3 \mathrm{~h}$ followed by $15 \mathrm{~min}$ of ATP ( 5 $\mathrm{mM}$ ) before harvesting. Conditioned media (CM) were collected for exosome isolation.

3) Exosomes. Cultured cells were maintained in media containing exosome-depleted FBS (cat\# EXO-FBS50A-1, SBI System Biosciences). Mouse primary microglia were treated with PFF for $24 \mathrm{~h}$ in the presence or absence of mdivi-1, and further cultured for $36 \mathrm{~h}$ after PFF withdrawal. To activate microglia, cells were treated with LPS $(1 \mu \mathrm{g} / \mathrm{ml})$ for $3 \mathrm{~h}$ followed by $15 \mathrm{~min}$ of ATP $(5 \mathrm{mM})$ before harvesting. Conditioned media (CM) were collected for exosome isolation. Cell culture media $(20 \mathrm{ml})$ from two $100 \mathrm{~mm}$ plates of primary microglia was collected $24 \mathrm{~h}$ after PFF removal, centrifuges at $3000 \times g$ at room temperature for $15 \mathrm{~min}$ to remove cell debris. Exosomes in the resultant supernatant was precipitated using ExoQuick-TC PLUS Exosome Purification Kit (Cat\# EQPL10TC-1, SBI System Biosciences) according to the manufacturer's instructions. Exosome pellets were re-suspended in culture medium for cell treatment. To visualize exosomes, pellets of exosomes were re- 
suspended in sterile water and transferred to carbon-coated 200-mesh copper electron microscopy grids and incubated for $10 \mathrm{~min}$ at room temperature. Exosomes were then incubated with $2 \%$ phosphotungstic acid for 3 min. Micrographs were observed under a transmission electron microscope (Phillip CM120).

\section{Cell transfection}

Cells were transfected with plasmids $(0.3 \mu \mathrm{g} /$ well for 24 well plate and $1.5 \mu \mathrm{g} /$ well for 6 -well plate) using either Lipofectamine $^{\mathrm{Tm}} 3000$ (Thermo Fisher Scientific) or jetPRIME $^{\text {ma }}$ DNA and siRNA Transfection Reagent (Polyplustransfection ${ }^{\circ} \mathrm{SA}$ ) following the manufacture's protocol.

\section{Immunofluorescence}

Cells were grown on borosilicate cover slips pre-coated with poly-D-lysine in 24-well plates. Prior to immunostaining, cells were fixed with $4 \%$ formaldehyde (Thermo Scientific $^{\text {TM }}$ Pierce $^{\text {Tw }}, \# 28906$ ), in warm cell culture media at $37^{\circ} \mathrm{C}$ for $20 \mathrm{~min}$. Please refer to the table in Additional file 1 for a list of primary antibodies and dilutions used. Corresponding Alexa Fluor ${ }^{\circ}(350,488,586$, and 633) conjugate secondary antibodies (Molecular Probes) were used at 1:500-1:1000 dilution. Slides were mounted using Prolong ${ }^{\text {Tx }}$ gold anti-fade mount with or without DAPI (Molecular Probes). Images were captured using Olympus Fluoview 1200 confocal microscope (with the exception of live cell imaging, which was Olympus Fluoview10i automated confocal laser-scanning microscope).

\section{Immunoblotting}

For cytosolic samples, cells were lysed with RIPA buffer (150 mM NaCl,1\%(v/v) IGEPAL, 0.5\% Sodium Deoxycholate, $0.1 \%$ SDS, $50 \mathrm{mM}$ Tris, $\mathrm{pH}$ 8.0) containing $1 \mathrm{X}$ Halt Protease and Phosphatase Inhibitor (Thermo Scientific), dounced for 20-30 times in a $1 \mathrm{~mL}$ glass homogenizer and centrifuged at $16,000 \times g$ for $15 \mathrm{~min}$ at $4{ }^{\circ} \mathrm{C}$. Supernatants were collected and 30-45 $\mu$ g of protein per well (depending on respective antibodies) were separated in SDS-PAGE.

For experiments related to exosome release, cells were sonicated in RIPA buffer. To measure the amount of exosomes release, exosomes were extracted from same amount of culture medium and immunoblotted for exosomal markers (Alix and Tsg101). To quantify the levels of $\alpha$-syn in exosomes, the same amount of protein from exosomes $(40 \mu \mathrm{g})$ were loaded. Proteins were separated by SDS-PAGE and then transferred onto nitrocellulose membranes. The blots were then incubated overnight at $4{ }^{\circ} \mathrm{C}$ with following primary antibodies: anti-Alix, anti-Tsg101, and anti-alpha synuclein. Secondary antibodies conjugated with horseradish peroxidase (HRP) were used, and immunoreactivity was visualized with chemiluminescence (SuperSignal Ultra, Pierce, Rockford, IL,USA). Protein bands were analyzed and quantified using Scion Image system (Scion Corporation).

\section{Mitochondrial morphology}

N27 stable cells were grown on poly-D-lysine-coated glass coverslips. Mitochondria were visualized with transfected DsRed-Mito as we previously described [15] and images were captured using Olympus Fluoview 1200 confocal microscope. Mitochondrial morphology was quantified blinded using Image J [15]. More than 500 clearly identifiable mitochondria from randomly selected $30-50$ cells per experiment were measured in four independent experiments. Roundness: $4 \times([$ Area $]) /\left(\pi \times[\text { Major axis }]^{2}\right)$. Aspect ratio is a measurement of major / minor axes [15], using Image)', (https://imagej.nih.gov/ij/). Both of these values approach 1 as the particle becomes circular.

\section{Mitochondrial membrane potential $\left(\Delta \Psi_{\mathrm{m}}\right)$}

$\Delta \Psi \mathrm{m}$ in $\mathrm{N} 27$ was quantified using $50 \mathrm{nM}$ tetramethylrhodamine methyl ester (TMRM) as previously described [15]. As a positive control, cells were treated with $20 \mu \mathrm{M}$ carbonyl cyanide 4-(trifluoromethoxy) phenylhydrazone (FCCP) to collapse $\Delta \Psi \mathrm{m}$. Fluorescent signal was analyzed by BD Accuri C6 flow cytometer using FL-2 channel.

\section{Reactive oxygen species (ROS) quantification}

Cellular ROS was measured using the superoxide indicator dihydroethidium (DHE, Invitrogen) as described [55]. Briefly, N27 stable cells grown in 24-well plates were treated with $10 \mu \mathrm{M} \mathrm{DHE}$ in cell culture medium and incubated for $20 \mathrm{~min}$ at $37^{\circ} \mathrm{C}$. The dye was then washed, cells were trypsinized, and analyzed using flow cytometry (BD Accuri C6),. As a positive control, cells were treated with $30 \mu \mathrm{M} \mathrm{H}_{2} \mathrm{O}_{2}$.

Mitochondrial ROS was assessed using MitoSOX red (M36008, Molecular Probes). N27 stable cells were grown in 96-well plate and incubated with $2.5 \mu \mathrm{M}$ of MitoSOX working solution (in HBSS) at $37^{\circ} \mathrm{C}$ for 20 min. Cells were then washed three times with PBS and fluorescent intensity was measured using a plate reader (Biotek Synergy H1 Hybrid Multi-Mode Reader) at Ex/ Em 510/595. After which cells were washed twice with PBS, incubated with DAPI $(5 \mu \mathrm{g} / \mathrm{ml})$ in the dark at room temperature for $10 \mathrm{~min}$ and washes three times before the DAPI signal was quantified using the Biotek plate reader (Ex/Em 358/461). Treatment of $50 \mathrm{nM}$ rotenone, a mitochondrial complex I inhibitor, for $48 \mathrm{~h}$ was used as a positive control to generate mitochondrial ROS.

\section{Mitochondrial respiration}

Mitochondrial function in live cells was assessed using the Seahorse $\mathrm{XFe}_{96}$ Extracellular Flux Analyzer (Seahorse Biosciences Inc). Cells were grown in the Seahorse 96-well plates overnight for attachment. On the following day, cell 
culture medium was washed and replaced with $175 \mu$ of serum free assay medium (Dulbecco's Modified Eagle's Medium with - $5.5 \mathrm{mM}$ Glucose, $1.0 \mathrm{mM}$ Sodium Pyruvate, $4 \mathrm{mM}$ Glutamine, $2 \mathrm{mM}$ HEPES, $\mathrm{pH} 7.4$ ), incubated in a $37^{\circ} \mathrm{C}$ non- $\mathrm{CO}_{2}$ incubator for at least $30 \mathrm{~min}$ before being loaded into the analyzer. Mitochondrial respiration was measured using the Mito-Stress Test (Seahorse Biosciences Inc) as instructed by the manufacturer. Oligomycin $(1 \mu \mathrm{g} /$ $\mathrm{ml})$, FCCP $(0.5 \mu \mathrm{M})$, rotenone $(1 \mu \mathrm{M})$ and antimycin A $(1 \mu \mathrm{M})$ were sequentially added to cells to determine mitochondrial respiration. Each oxygen consumption rate data point refers to the mean rates during each measurement cycle, which consists of a mixing time of 30s followed by a data acquisition period of $3 \mathrm{~min}$. Three data points were acquired after each injection, and four data points were recorded for basal respiration [69]. For normalization, cells were fixed with $4 \%$ PFA, followed by incubation of DAPI $(80 \mu \mathrm{l} \mathrm{of} 5 \mu \mathrm{g} / \mathrm{ml}$ in PBS) for $10 \mathrm{~min}$. The plate was then washed 3 time with PBS, and fluorescent signal DAPI for was quantified at Ex/Em 358/461 nm using the Biotak Synergy H1 Hybrid Reader.

To calculate total ATP production rate, which, in cell, is the sum of ATP generated by oxidative phosphorylation and glycolysis. Proton production, measured as the extracellular acidification rate in the XFe96 analyzer, also include two sources: (1) pyruvate to lactate ${ }^{-}$conversion directly through glycolysis, and (2) $\mathrm{CO}_{2}$ to $\mathrm{HCO}_{3}{ }^{-}$reaction in the TCA cycle indirectly from pyruvate feeding into the process. In addition, the amount of ATP produced per glucose through glycolysis and oxidative pathways differs significantly. Therefore, instead of directly comparing extracellular acidification rate (ECAR) with oxygen consumption rate (OCR) as cell glycolytic/metabolic index, we adapted the calculation methods by Mookerjee and colleagues [44] to compare the ATP produced by both pathways.

$$
\begin{aligned}
& \text { Total ATP production }=A T P_{g l y c}+A T P_{(o x)} \\
& A T P_{\text {ox }}=\left[\text { OCR }(\text { coupled }) \times 2 P / O_{\text {oxphos }}\right] \\
& +\left[\text { OCR }_{\text {mito }} \times 2 P / O_{T C A}\right](P / O \text { defined as mol } \\
& \text { of ATP produced by per mol of oxygen atom) } \\
& A T P_{\text {glyc }}=\left(P P R_{\text {glyc }} \times A T P / \text { lactate }\right) \\
& +\left(\text { OCR }_{\text {mito }} \times 2 \mathrm{P} / \mathrm{O}_{\text {glyc }}\right) \\
& \text { (Glycolytic rate) } P P R_{g l y c}=E C A R_{\text {tot }} / \text { buffering power - } \\
& {\left[O C R_{\text {mito }} \times \max H^{+} / O_{2} \times\left(10^{p H-p K 1}\right) /\left(1+\left(10^{p H-p K 1}\right)\right)\right]} \\
& O C R_{\text {mito }}=O C R_{\text {tot }}-O C R_{R / A}
\end{aligned}
$$

\section{Quantification of autophagic vesicles}

The analysis of autophagy flux in stable HeLa cells expressing mRFP-GFP-LC3 was performed as described
[8]. Green vesicles represent autophagosomes because when the autophagosome fuses with the lysosomes, the $\mathrm{pH}$ sensitive GFP signal is quenched by the acidic environment in the lysosomes. Red vesicles are made up of both autophagosomes and autolysosomes. The number of autolysosomes was obtained by subtracting the number of green vesicles from that of the red vesicles. For analysis, cells were imaged with an Olympus Fluoview with 60x time objective, autophagosomes and autolysosomes from at least 50 cells per treatment group were counted using ImageJ. For N27 cells, autophagy blockage was assessed through quantification of LC3-mcherry puncta together with the immunostained p62 puncta.

\section{Proteinase $\mathrm{K}$ digestion}

To determine the formation of aggregation in cells, Proteinase $\mathrm{K}$ digestion was performed. Freshly fixed cultured cells were washed $3 \mathrm{X} 5 \mathrm{~min}$ with PBS, then treated with Proteinase K ( 0.34 U/ml, Sigma P4850). The plates were then incubated in the dark at room temperature for $10 \mathrm{~min}$ with gentle shaking, followed by 3X5min washes with PBS and subsequently immunostained for $\alpha$-syn.

\section{Phospho4E-BP-1 immunoblotting}

N27 stable cells were transfected with Drp1 siRNA (10 $\mathrm{nM})$ or scramble control $(10 \mathrm{nM})$ overnight and then induced with PonA for $48 \mathrm{~h}$. Overnight rapamycin treatment $(1 \mu \mathrm{M})$ was used as a control to inhibit mTOR. Cells were then harvested for western blotting. The phosphorylated form of mTOR substrate protein 4E-BP1 was probed using Phospho-4E-BP1 (Thr37/46) (236B4) Rabbit monoclonal antibody (Cell Signaling Technology, catalogue \#2855), 1:500 dilution, and subsequently probed with goat anti-rabbit IgG HRP conjugate (Biorad) with 1:5000 dilution.

\section{Statistics}

Data represent mean \pm SEM. For normally distributed data, differences between means were analyzed using one-way ANOVA, followed by Newman-Keuls post hoc testing for pairwise comparison. The null hypothesis was rejected when the $p$ value $<0.05$.

\section{Results \\ Drp1 inhibition reduces mitochondrial fragmentation induced by a-syn in rat dopaminergic neuronal cells}

To have an experimental model stably overexpressing a neurotoxic protein such as $\alpha$-syn, we used an ecdysone inducible system to overexpress human wild-type $\alpha$-syn in the rat dopaminergic neuron cells N27. The ecdysone inducible approach provides a tight regulation of the transgene expression, a strategy that we previously used successfully to generate inducible cells overexpressing 
PINK1 [15]. As shown in Additional file 1: Figure S3, the cell population with inducible $\alpha$-syn expression was selected by fluorescence activated cell sorting (FACS) after using a Cy3-mRNA probe specific to human $\alpha$-syn mRNA. The inducible expression of $\alpha$-syn was then further characterized using immunocytochemistry and western blotting (Fig. 1, Additional file 1: Figure S3). Based on our time-course and dose-response studies, a treatment of $20 \mu \mathrm{M}$ of Ponasterone A (PonA, an ecdysone analog) for $48 \mathrm{~h}$ was chosen to induce $\alpha$-syn expression - unless otherwise specified in some specific experiments.

After the successful generation of these stable $\alpha$-syn dopaminergic neuronal cells, we first assessed the impact of $\alpha$-syn on mitochondrial morphology. Using DsRedMito transfection to visualize mitochondria, we observed that these organelles were fragmented in cells with $\alpha$-syn overexpression (Fig. 1a). However, stable cells with empty vector control displayed tubular mitochondria. This observation appeared to be mediated by Drp1 because increased levels of this fission protein were observed at the mitochondrial and total levels, as demonstrated using immunocytochemistry (Fig. 1a) and immunoblotting (Fig. 1b), respectively. To investigate the effects of Drp1 inhibition on mitochondrial fragmentation induced by $\alpha$-syn, we used complementary genetic and pharmacological approaches to reduce Drp1 function as we previously described $[4,15,56]$. First, we transfected cells with siRNA-Drp1, which achieved approximately $70-80 \%$ of Drp1 knockdown efficiency (Additional file 1: Figure S4). Second, we transfected cells using the dominant negative mutant Drp1-K38A. Third, the small molecule mitochondrial division inhibitor-1 (mdivi-1). As demonstrated morphologically (Fig. 1c-e) and quantitatively (Fig. 1f), all three strategies blocked mitochondrial fragmentation induced by $\alpha$-syn. Of note, siRNA-Drp1 did not appear to reduce the levels of $\alpha$-syn as compared to the group that received scrambled siRNA. To quantify more objectively the levels of $\alpha$-syn in these two groups of cells, we performed immunoblotting and confirmed that the levels of $\alpha$-syn between cells transfected with scramble-siRNA and Drp1siRNA were not statistically different $(6.72 \pm 0.31$ vs $6.16 \pm 1.76$, data represent mean \pm SEM from 3 independent experiments using actin as a loading control).

\section{Drp1 inhibition improves mitochondrial function and reduces oxidative stress induced by a-syn}

Based on the observation that inducible $\alpha$-syn-WT impaired mitochondrial morphology (Fig. 1), we asked whether mitochondrial function was also impaired in this cell model, and if so, would blocking Drp1 attenuate such dysfunction. To this end, we evaluated multiple mitochondrial function parameters. First, we measured mitochondrial membrane potential $\left(\Delta \Psi_{m}\right)$, which is established by the electrochemical gradient from redox reactions generated by the mitochondrial electron transport chain (ETC). This gradient is responsible for driving ATP production, and therefore a decrease in $\Delta \Psi_{m}$ is indicative of mitochondrial dysfunction. Using flow cytometry, we quantified fluorescent intensity of tetramethylrhodamine (TMRM) taken up by mitochondria in N27 cells. After $48 \mathrm{~h}$ of induction, $\alpha$-syn significantly reduced $\Delta \Psi_{m}$. Drp1 inhibition, either mediated by gene silencing (Fig. 2a) or the small inhibitor mdivi-1 (Fig. 2b), completely prevented this deficit. Second, to directly measure mitochondrial function, we quantified mitochondrial respiration using the Seahorse XFe96 Extracellular Flux Analyzer (Fig. 2c). We calculated ATP production rate by either oxidative phosphorylation or glycolysis. Figure $2 \mathrm{~d} \&$ e show that $\alpha$-syn specifically reduced mitochondrial respiration but not glycolysis. siRNA-Drp1 or mdivi-1 attenuated this deficit. Next, we evaluated mitochondrial spare respiratory capacity (SRC), which represents the ability of mitochondria to provide substrate supply and electron transport in response to an increase in energy demand. $\alpha$-syn suppressed SRC and siRNA-Drp1 (Fig. 2f) and mdivi-1 (Fig. $2 \mathrm{~g})$ preserved SRC despite the presence of $\alpha$-syn.

An impairment in mitochondrial function invariably would lead to free radical production such as reactive oxygen species (ROS). To determine whether such ROS production would originate from mitochondria resulting in a higher total cellular ROS, we quantified MitoSOX Red and Dihydroethidium (DHE) signals to detect mitochondrial superoxide and cellular ROS levels, respectively (Fig. 2h-k). Rotenone, a complex I inhibitor, was used as a positive control to generate ROS from the ETC blockade. Consistent with its inhibitory effect on mitochondrial function, $\alpha$-syn increased ROS levels, an adverse effect that was blunted by Drp1 inhibition (Fig. 2h-k). Taken together, these mitochondrial studies support the negative effects of $\alpha$-syn on the mitochondrial ETC and that blocking Drp1 is protective.

\section{Drp1 inhibition attenuates autophagic blockade and protein aggregation in dopaminergic N27 neuronal cells with inducible $a$-syn}

Protein aggregation is a common pathological feature of $\alpha$-syn. In our cell model proteinase-K resistant $\alpha$-syn aggregates were detectable 2 days after gene induction (Fig. 3a, arrows). Knocking down Drp1 with siRNA drastically reduced such protein aggregation (Fig. 3b, c). This genetic approach provided data consistent with our previous publication where $\alpha$-syn-A53T accumulation in rats was significantly reduced by mdivi-1 [4]. Because autophagy is a primary pathway by which $\alpha$-syn is degraded [67], one possible mechanism by which Drp1 

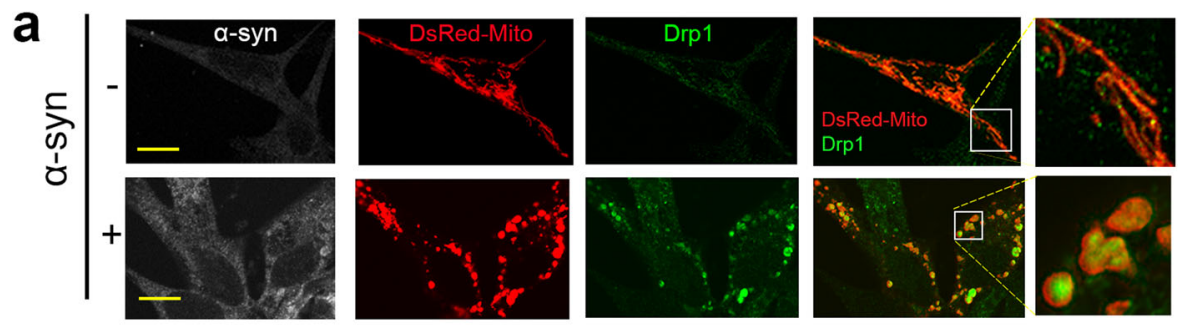

b
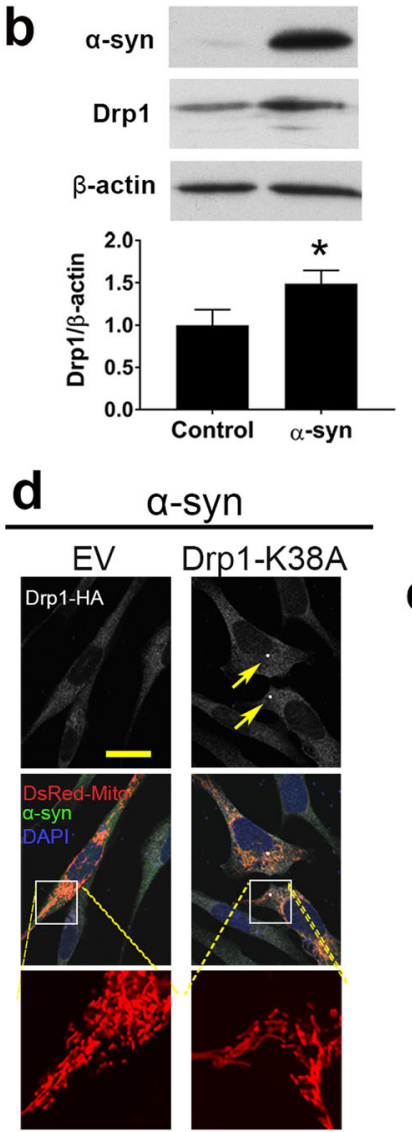

e

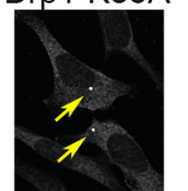

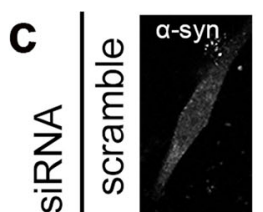
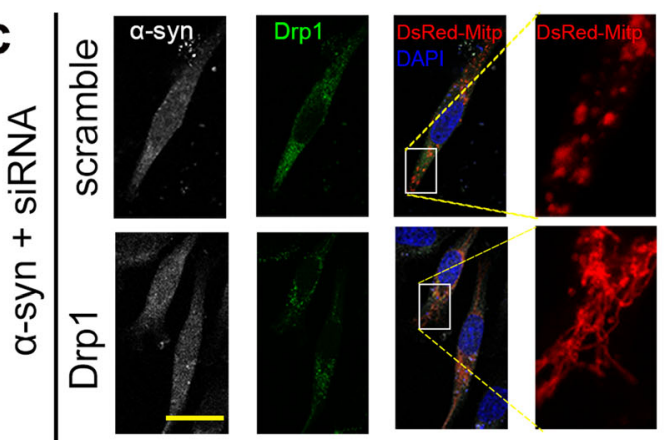

f
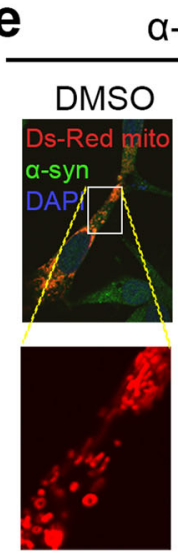

a-syn

mdivi-1
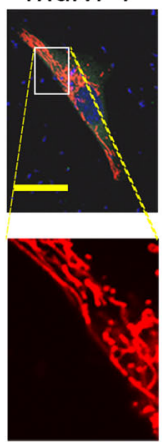
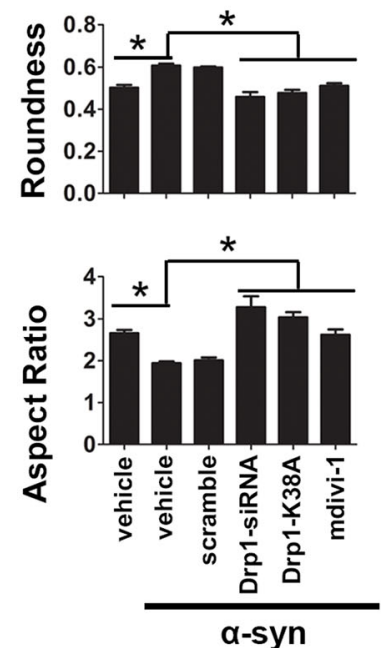

Fig. 1 Drp1 inhibition reduces mitochondrial fragmentation induced by a-syn in rat dopaminergic neuronal cells. a Stable rat dopaminergic N27 cells with ecdysone-inducible system containing human wild type SNCA were transfected with DsRed-Mito overnight, treated with $20 \mu \mathrm{M}$ PonA for $48 \mathrm{~h}$ to induce a-syn expression, followed by immunostaining for a-syn (gray) and Drp1 (green). Representative images show the effects of asyn on mitochondrial morphology and Drp1 colocalization with mitochondria. b Total levels of a-syn and Drp1 in stable cells expressing empty vector control or SNCA after $48 \mathrm{~h}$ of 20 MM PonA treatment were assessed using immunoblotting. c N27 cells were co-transfected with DsRedMito and rat siRNA-Drp1 or scramble control overnight, then induced with PonA for $48 \mathrm{~h}$. Representative images showing siRNA-Drp1, but not scramble control, attenuated mitochondrial fragmentation induced by a-syn. d As a complementary genetic approach, N27 cells were cotransfected with the dominant-negative mutation Drp1-K38A (HA- tagged) and DsRed-Mito, then induced with PonA for $48 \mathrm{~h}$ before immunostained for HA and a-syn. Representative images showing mitochondrial morphology in Drp1-K38A expression (arrows pointing to the characteristic Drp1 puncta formation) cells versus a-syn overexpression alone. e N27 cells were transfected with DsRed-Mito, and induced with PonA plus mdivi-1 (10 $\mu \mathrm{M})$ or vehicle control (DMSO) for $48 \mathrm{~h}$. Scale bars: $20 \mu \mathrm{m}$. Imaging data from c-e were quantified for mitochondrial morphology using Image J and summarized quantitatively in f. Both the values of "roundness" and "aspect ratio" approach 1 as the particle becomes circular. Data represents mean \pm SEM, analyzed by one-way ANOVA ( $n=4$ or 5 independent experiments with $>500$ mitochondria /group quantified for each experiment), followed by Newman-Keuls post hoc test. * $p<0.05$

inhibition reduced protein aggregation is by improving autophagic flux. Since LC3-II is selectively associated with autophagosomes, LC3-II or LC3-decorated vesicles has been widely used to indicate autophagosome levels or contents in cells [33]. The levels of p62 as a selective autophagy substrates inversely correlate with autophagic flux [5]. To test the hypothesis Drp1 inhibition would attenuate autophagic impairment induced by $\alpha$-syn, we quantified the levels of LC3-II and p62 levels in the N27 cells with inducible $\alpha$-syn expression. To achieve this 

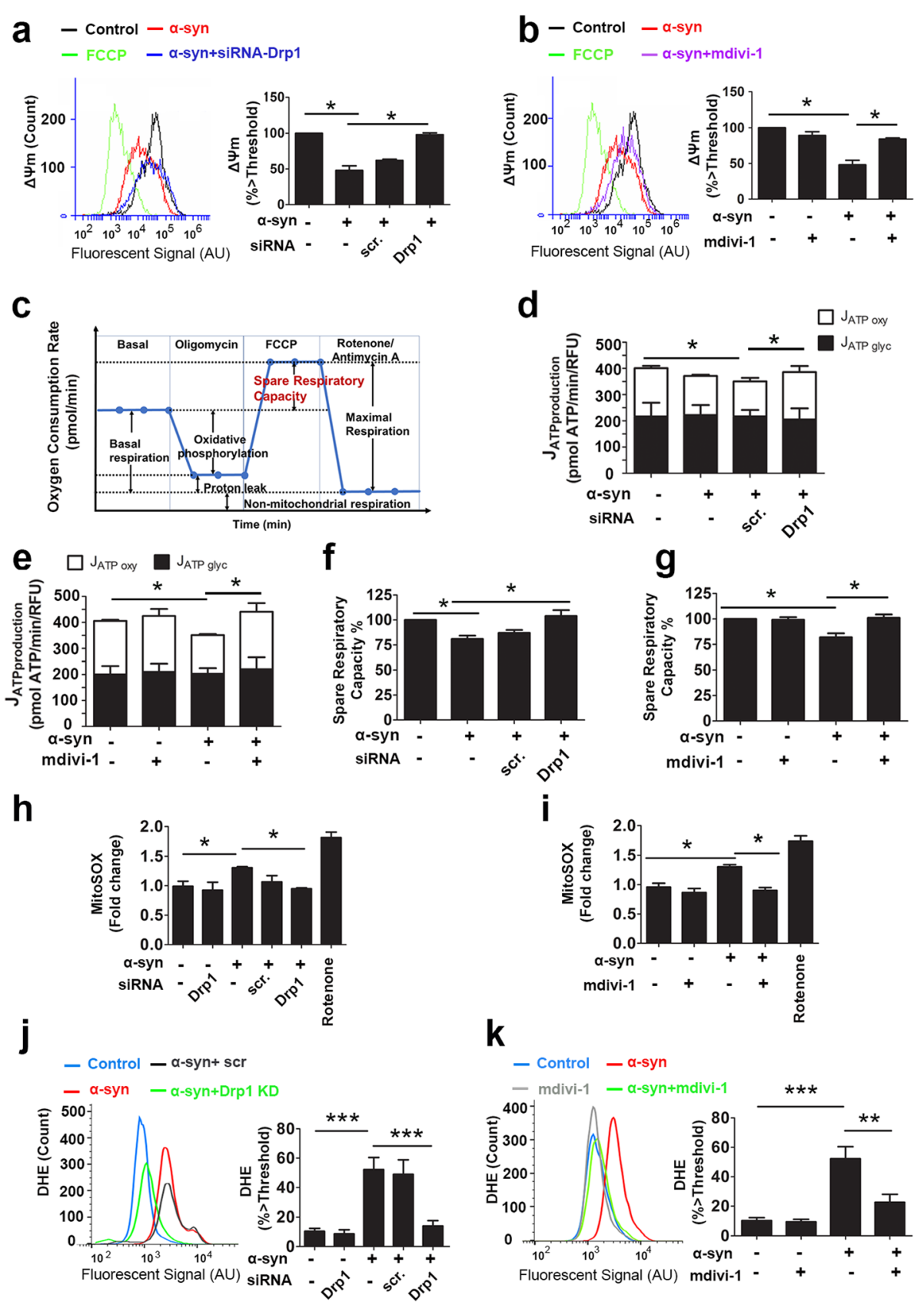

Fig. 2 Drp1 inhibition improves mitochondrial function and reduces oxidative stress induced by a-syn. Drp1 inhibition was performed as described in Fig. 1 and the expression of a-syn was induced with $20 \mu \mathrm{M}$ PonA for $48 \mathrm{~h}$ before the following experiments were performed: $\mathbf{a}$ \& $\mathbf{b}$ Mitochondrial membrane potential $(\Delta \psi \mathrm{m})$ was assessed using TMRM $(50 \mathrm{nM})$, and fluorescent intensity was analyzed using flow cytometry. The uncoupler agent carbonyl cyanide 4- (trifluoromethoxy) phenylhydrazone (FCCP, $20 \mu \mathrm{M}$ ) was used as positive control to collapse $\Delta \psi \mathrm{m}$ to establish the threshold. Signal intensity (AU, arbitrary unit) was expressed as \% above this threshold. c-g Mitochondrial respiration and glycolysis in live cells were assessed by measuring oxygen consumption rate and extracellular acidification rate using the XFe96 Extracellular Flux Analyzer. Sequential injections of oligomycin (to inhibit oxygen consumption mediated by ATP synthase), FCCP (an uncoupler to induce maximal OCR), Rotenone/Antimycin (to inhibit complex I and III, respectively). Spare Respiratory Capacity was calculated as \%= (Maximal Respiration) / (Basal Respiration) $\times 100$. a-syn overexpression reduced ATP production rate through oxidative phosphorylation, but not through glycolysis (d \& e) as well as impaired spare respiratory capacity $(\mathbf{f} \& \mathbf{g})$. Drp1 knockdown and mdivi-1 conferred protection. MitoSox red dye (h \& i) and dihydroethidium $(\mathrm{DHE}, \mathbf{j} \& \mathbf{k})$ were used to measure mitochondrial and total cellular ROS, respectively, and signal intensity was quantified by plate reading and flow cytometry respectively. Data represent the mean \pm SEM, one-way ANOVA $(n=4)$, followed by Newman-Keuls post hoc test. ${ }^{*} p<0.05{ }^{* *} p \leq 0.02$, *** $p<0.001$ 

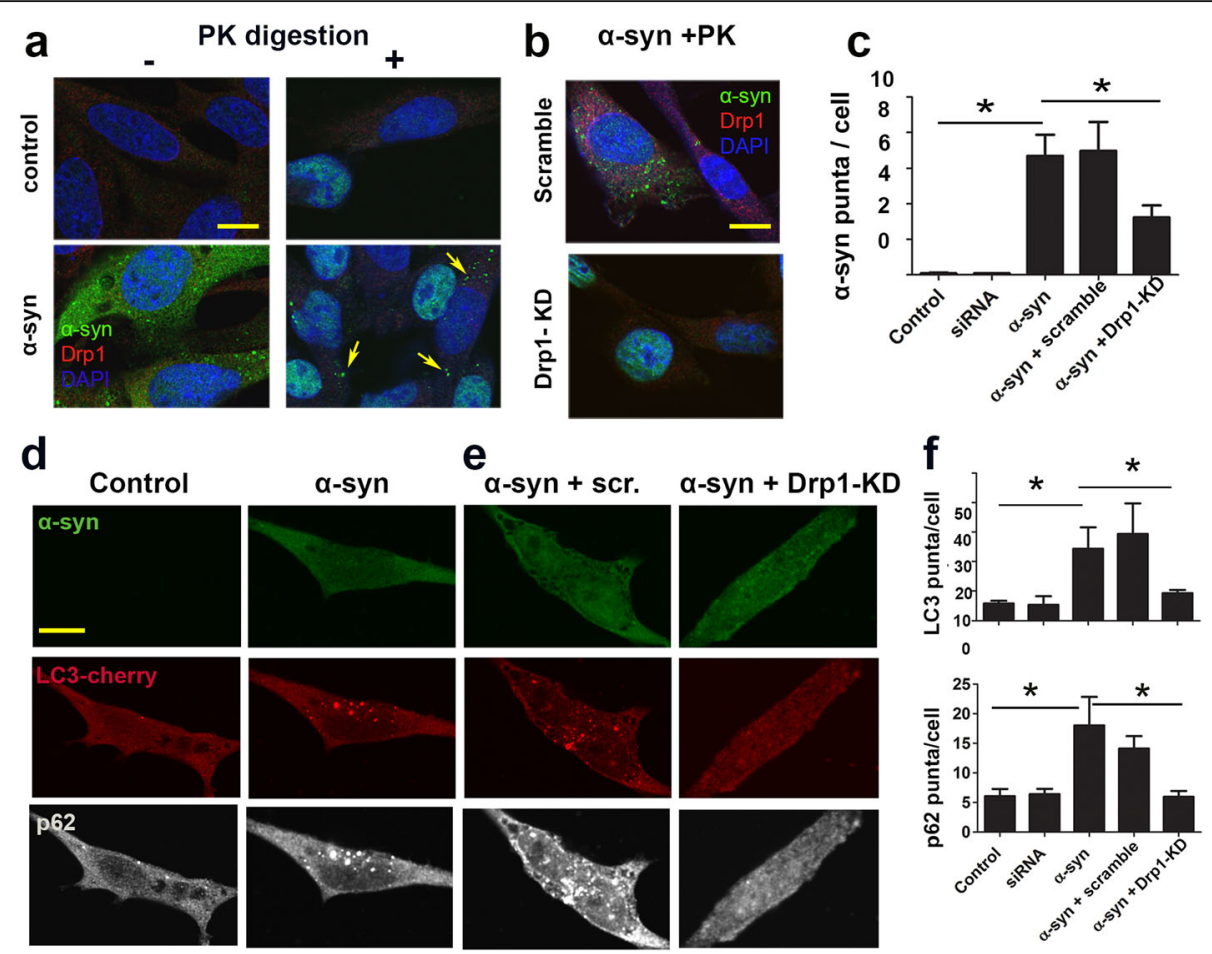

Fig. 3 Drp1 inhibition attenuates autophagic blockade and protein aggregation in dopaminergic N27 neuronal cells with inducible a-syn. a \& $\mathbf{b}$ Stable N27 cells were transfected with siRNA-Drp1 or scramble control for $24 \mathrm{~h}$, then induced with PonA for an additional $48 \mathrm{~h}$, fixed and immediately incubated with Proteinase-K (PK) for digestion. Drp1 and a-syn were then immunostained (arrows pointing to the characteristic PK resistant a-syn puncta) c PK resistant a-syn punta were quantified using Image J. d \& e Stable N27cells were co-transfected with LC3-cherry plus either siRNA-Drp1 or scramble control for $24 \mathrm{~h}$, then induced with PonA for an additional $48 \mathrm{~h}$. Cells were then immunostained for a-syn and p62. $\mathbf{f}$ LC3 and p62 punta were quantified using Image J. Data represents mean $\pm \mathrm{SEM}, n=3-4$ independent experiments with 20-30 cells per treatment group were counted in each experiment, analyzed by one-way ANOVA, followed by Newman-Keuls post hoc test. ${ }^{*} p<0.05$. ${ }^{*} p<0.05$ Scale bar: $10 \mu \mathrm{m}$

objective, we transfected N27 cells with either siRNADrp1 or scramble control for $24 \mathrm{~h}$ and then induced $\alpha$ syn for $48 \mathrm{~h}$, followed by immunoblotting for p62and LC3I/II. The levels of p62 were significantly elevated after $\alpha$-syn induction. siRNA-Drp1, but not scramblesiRNA, significantly reduced the levels of p62 in cells with $\alpha$-syn overexpression but did not change the baseline levels of p62 in cells without $\alpha$-syn overexpression (Additional file 1: Figure S5). Of note, endogenous levels of LC3 in N27 cells were too low to be detected reliably. Therefore, we co-transfected N27 cells with LC3-cherry plasmid to facilitate quantification of LC3 puncta in these neuronal cells. As seen in Fig. 3d-f, $\alpha$-syn significantly increased the number of LC3 puncta, supporting accumulation of autophagosomes. Using immunocytochemistry to simultaneously detect p62 in these cells, we also observed an increase in p62 puncta levels, indicating a blockade of autophagy. (Fig. 3d-f). These data suggest that autophagy-lysosomal pathway is compromised in $\alpha$ syn-expressing cells, consistent with previous reports $[16,23]$. The accumulation of these autophagic proteins, however, was significantly attenuated by siRNA-Drp1 (Fig. 3d-f), but not scramble siRNA control, suggesting that Drp1 inhibition restores autophagy-lysosomal activity or autophagic flux.

\section{Drp1 inhibition prevents autophagy flux impairment induced by a-syn in autophagy reporter HeLa cells} As illustrated in our schematic diagram, autophagy plays a critical role in removing misfolded proteins (Fig. 4a). An impairment in autophagy has been well-established to result in accumulation of protein aggregation [57]. We recently demonstrated that pharmacological blocking of Drp1 dramatically reduced $\alpha$-syn aggregates in nigral DA neurons of rats overexpressing $\alpha$-syn [4]. However, it was not determined whether such protective effect was mediated through autophagy. Although data presented in Fig. 3d-f support the role of Drp1 in autophagy, to more directly monitor autophagy flux in the present study, we utilized the autophagy reporter HeLa cells with stable overexpression of mRFP-GFP-LC3 (Fig. 4b). These cells were designed to monitor autophagy flux [32]. mRFP-GFP-LC3 vesicle analysis allows us to monitor autophagosome synthesis and autophagosome-lysosome fusion by labelling autophagosomes (green and red) and autolysosomes (red), 


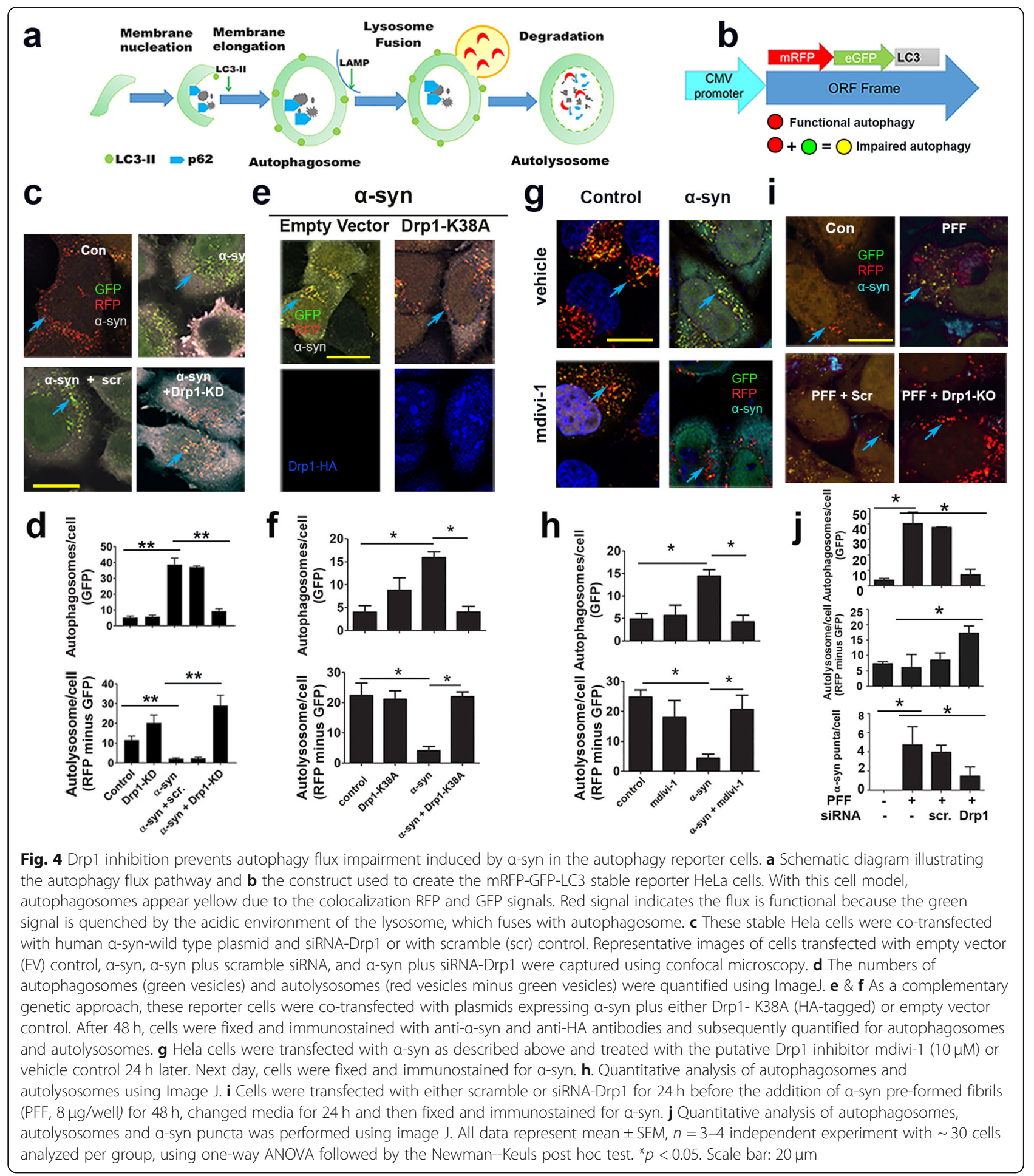

since the low lysosomal pH quenches the GFP signal. Previously, $\alpha$-syn was shown to impair autophagic flux with increased autophagosome accumulation and reduced autophagosome-lysosome fusion [23]. To investigate whether blocking Drp1 would improve autophagy flux impaired by $\alpha$-syn, we co-transfected these autophagy reporter cells with wild type human $\alpha$-syn in the presence or absence of siRNA-Drp1 or siRNA-scramble control (Fig. 4c). After $48 \mathrm{~h}$, cells were immunostained for $\alpha$-syn and the number of autophagosomes and autolysosomes were quantified in these immunoreactive cells in a blinded manner. 
As demonstrated in Fig. 4c \& d, Drp1 knockdown, but not scramble control, significantly attenuated autophagosome accumulation and enhanced autolysosomal levels in the cells with $\alpha$-syn overexpression, indicating that Drp1 knockdown alleviates autophagic impairment induced by $\alpha$-syn. Using another genetic approach to reduce Drp1 function, we transfected cells with the mutant Drp1-K38A dominant negative (Fig. 4e \& f). In cells with Drp1-K38A expression as evidenced by immunostaining of the HA-tag, autophagy flux was significantly improved despite the co-transfection of $\alpha$-syn. As a comparison to genetic approaches, we also assessed the effects of the small molecule mitochondrial division inhibitor-1 (mdivi-1) in this study. Figure $4 \mathrm{~g} \& \mathrm{~h}$ demonstrate that mdivi-1 also protected against $\alpha$-syninduced autophagy blockade.

Human $\alpha$-syn preformed fibrils (PFF) has been used in recent years to induce the release of exosomes and the spread of $\alpha$-syn from one cell to another in vitro [24, 40, 65] and in vivo [40]. Small seeds of PFF generated from recombinant $\alpha$-syn can be endocytosed by neurons where it recruits endogenous $\alpha$-syn to form phosphorylated and insoluble aggregates [65]. We obtained $\alpha$-syn monomers from the Michael J. FOX Foundation and generated PFF according to the accompanying protocol. With transmission electron microscopy (TEM), we confirmed the morphology and size of PFF and its sonicated form (Additional file 1: Figure S6). Using the autophagy reporter HeLa cells, we confirmed that PFF blocked autophagy flux and siRNA-Drp1 attenuated this impairment (Fig. 4i \& j). Furthermore, this treatment also reduced $\alpha$-syn protein aggregation (Fig. 4i \& j). Together, in a cell model designed to monitor autophagy flux, our genetic and pharmacological data provide strong evidence that blocking Drp1 alleviates the negative impact of $\alpha$-syn on autophagy flux and therefore supporting a novel protective mechanism of Drp1 inhibition.

\section{Drp1 inhibition attenuates lysosomal impairment and inhibits mTOR activity}

To investigate how and at what stage of autophagy flux Drp1 inhibition has an impact on, we transfected the autophagy reporter mRFP-GFP-LC3 HeLa cells (Fig. 5a) with siRNA-Drp1 or scramble control and then treated them with chloroquine to block lysosomal function, as evidenced by a reduction in autolysosomes (Fig. 5b) and an increase in autophagosomes (Fig. 5c). These alterations were attenuated by Drp1 inhibition, suggesting a partial improvement in lysosomal function, however, a direct measure of lysosome function is needed to confirm this effect. Interestingly, the number of autophagosomes remained relatively high in the cells with higher levels of autolysosomal activity under Drp1 inhibition (Fig. 5c). This result suggests that Drp1 inhibition might also promote the formation of autophagosomes. Therefore, in theory, Drp1 inhibition enhances autophagy flux by increasing both the levels of autophagosomes and the function of lysosomes. To gain additional mechanistic insights into the observed higher autophagosome levels, we transfected stable N27 cells were with siRNA-Drp1, followed by $\alpha$-syn induction for 2 days and then cells were collected for immunoblotting to assess mTOR activity (which inhibits autophagy) by quantifying the levels of phosphor4E-BP1 (Fig. 5d\&e), which is a downstream substrate of mTOR. Consistent with previous study, we observed $\alpha$ syn activated mTOR (Fig. 5d\&e), and strikingly, knocking down Drp1 inhibited mTOR activity to an equivalent extent as rapamycin, an mTOR inhibitor. Together, our preliminary data provide a highly novel evidence that Drp1 inhibition increases autophagy flux by a combination of increasing the formation of autophagosomes and perhaps the function of lysosomes as well.

\section{Blocking Drp1 reduces exosome release from SH-SY5Y cells treated with PFF}

Autophagosome can either fuse with lysosomes for degradation or fuse with the endosomal multivesicular bodies (MVBs) to form amphisome [60]. Upon fusion of amphisome or MVBs with the plasma membrane, exosomes are secreted as extracellular vesicles [71]. Impaired autophagy flux, therefore, would increase the release of exosomes. Based on the observations described above demonstrating that blocking Drp-1 enhanced autophagy flux and inhibited $\alpha$-syn aggregation, we hypothesized that Drp1 inhibition may also reduce exosome release. Because N27 cells release undetectable levels of exosomes, we used SH-SY5Y to test this hypothesis. First, we performed Drp1 knockdown and then treated cells with PFF, followed by collecting conditioned medium and extracted exosomal fraction (EF), which was then used to treat another group of SH-SY5Y cells (see schematic diagram in Fig. 6a). Images obtained from transmission electron microscopy (TEM) revealed that EF was enriched with micro-vesicles 50-100 nm (Fig. 6b), which is consistent with the size of exosomes. Strikingly, similar to the donor cells treated with PFF (Fig. 6c), the recipient cells treated with EF for 4 days also showed strong signal for $\alpha$-syn (Fig. 6c). These results indicate that exosomes released from PFF treated donor neurons can be taken up by the recipient neuronal cells to serve as seeds to induce aggregation of $\alpha-$ syn. However, in cells with Drp1-knockdown, the appearance of $\alpha$-syn in the donor and recipient cells was much reduced (Fig. 6c). Next, using a similar experimental paradigm (Fig. 6d), we observed that mdivi- 1 also attenuated $\alpha$-syn aggregation in the donor and recipient cells (Fig. 6e). To quantify the observed alterations more objectively, equal volume of conditioned medium from each group of cells was probed for the content of exosomes (Fig. 6f) and the same amount of 

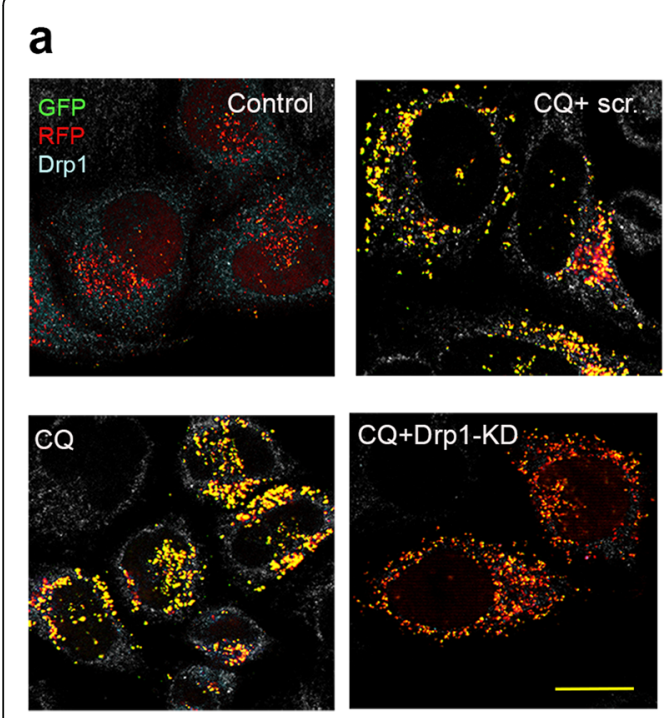

\section{b}

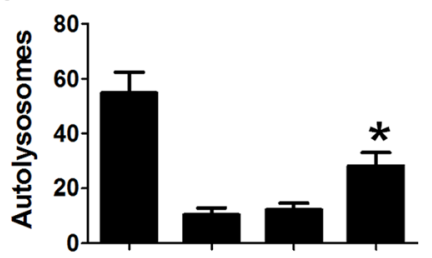

C

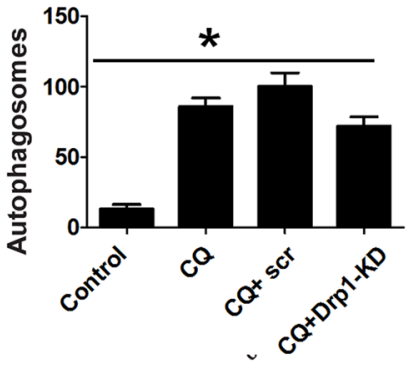

d
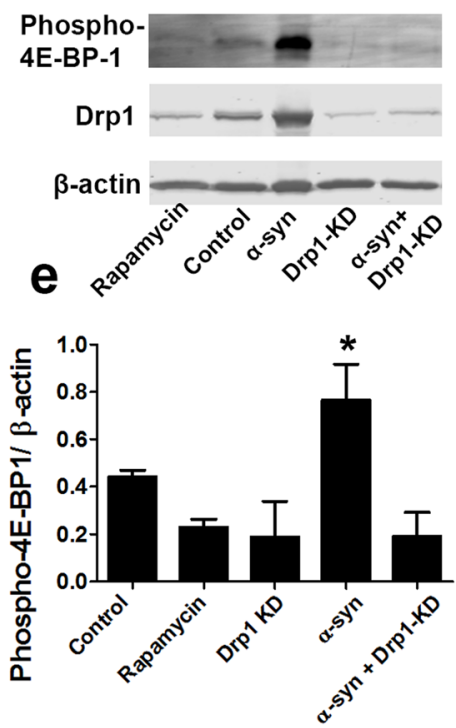

Fig. 5 Drp1 inhibition improves lysosomal function and inhibits mTOR activity. a - c Hela autophagy reporter cells were transfected with siRNADrp1 or scramble control and then treated with $25 \mu \mathrm{M}$ chloroquine (CQ) overnight (16 h) a Cells were immunostained with an Drp1 antibody. Images were captured and autophagosome/ autolysosome quantification b \& c was performed using ImageJ as described above. Data represent mean $\pm \operatorname{SEM}(n=3$ independent experiments). One-Way ANOVA with Newman-Keuls post-hoc analysis * $p<0.05$; compared to the vehicle control group. d \& e Stable N27 cells were transfected with siRNA-Drp1, and then induced with PonA ( $20 \mu \mathrm{M})$ next day to induce a-syn expression. $48 \mathrm{~h}$ after, cells were collected and lysed for western blot analysis $\mathbf{d}$. Phospho-4E-BP1 was probed and normalized to $\beta$-actin e Data represent mean \pm SEM ( $n=4-5$ independent experiments), One-way ANOVA followed by Newman-Keuls post-hoc testing * $p<0.05$; compared to the control group

exosomes from each group of cells was quantified for the levels of $\alpha$-syn (Fig. $6 \mathrm{~g}$ ). Our data strongly indicate that not only did Drp1 inhibition reduce exosome release induced by PFF, but also less $\alpha$-syn content was present in the released exosomes. These results are consistent with the mechanism of improving autophagy flux by Drp1 inhibition.

\section{Drp1 inhibition reduces protein aggregation induced by exosomes from PFF-treated microglia}

To investigate whether microglia would release exosomes and if so, whether blocking Drp1 would attenuate such a release from microglia, we treated primary mouse microglia with LPS, PFF or both in the presence or absence of mdivi-1 (Fig. 7a). Subsequently, conditioned media were collected for exosome isolation. The amount of exosome released from primary microglia was quantified using immunoblotting (Fig. 7b). It is evident that these treatments increased the release of exosomes from microglia and when combined with LPS, PFF further enhanced the release of exosomes and their content of $\alpha$ syn (Fig. 7c). To assess the spread of $\alpha$-syn from microglia to neuronal cells, exosomal fraction from LPS + PFF treated microglia was incubated with SH-SY5Y cells for 4 days to allow internalization to occur. As demonstrated in Fig. $7 d$, confocal images revealed $\alpha$-syn aggregation in these recipient neuronal cells and mdivi-1 reduced such aggregation. Due to the low level of efficiency of knocking down Drp1 in primary microglia, only the small molecule mdivi-1 was used. To further corroborate the role of Drp1 in microglial exosome release, we turned to the mouse microglial cell line BV2. These cells were transfected with siRNA-Drp1 or scramble control, followed by the PFF and LPS treatment as illustrated in Fig. 7e. Immunoblotting confirmed that Drp1 inhibition reduced the content of $\alpha$-syn in microglial exosomes (Fig. 7f), reduced exosome release from microglia (Fig. $7 \mathrm{~g}$ ) and reduce the spread of $\alpha$-syn to neuronal cells (Fig. 7h). In combination, results from primary microglia and BV2 cells indicate that microglia are capable of releasing $\alpha$-syn-containing exosomes, thereby spreading $\alpha$-syn to neurons. Blocking Drp1 significantly reduces these pathological processes.

\section{Discussion}

Mitochondrial dysfunction and impaired autophagy flux represent two major pathogenic mechanisms in PD. After the discovery of 1-methyl-4-phenyl-1,2,3,6-tetrahydropyridine (MPTP) as the chemical causing parkinsonism [35], mitochondrial dysfunction mediated by blockade of the electron transport chain has been quite well-investigated in PD. However, a more recent 


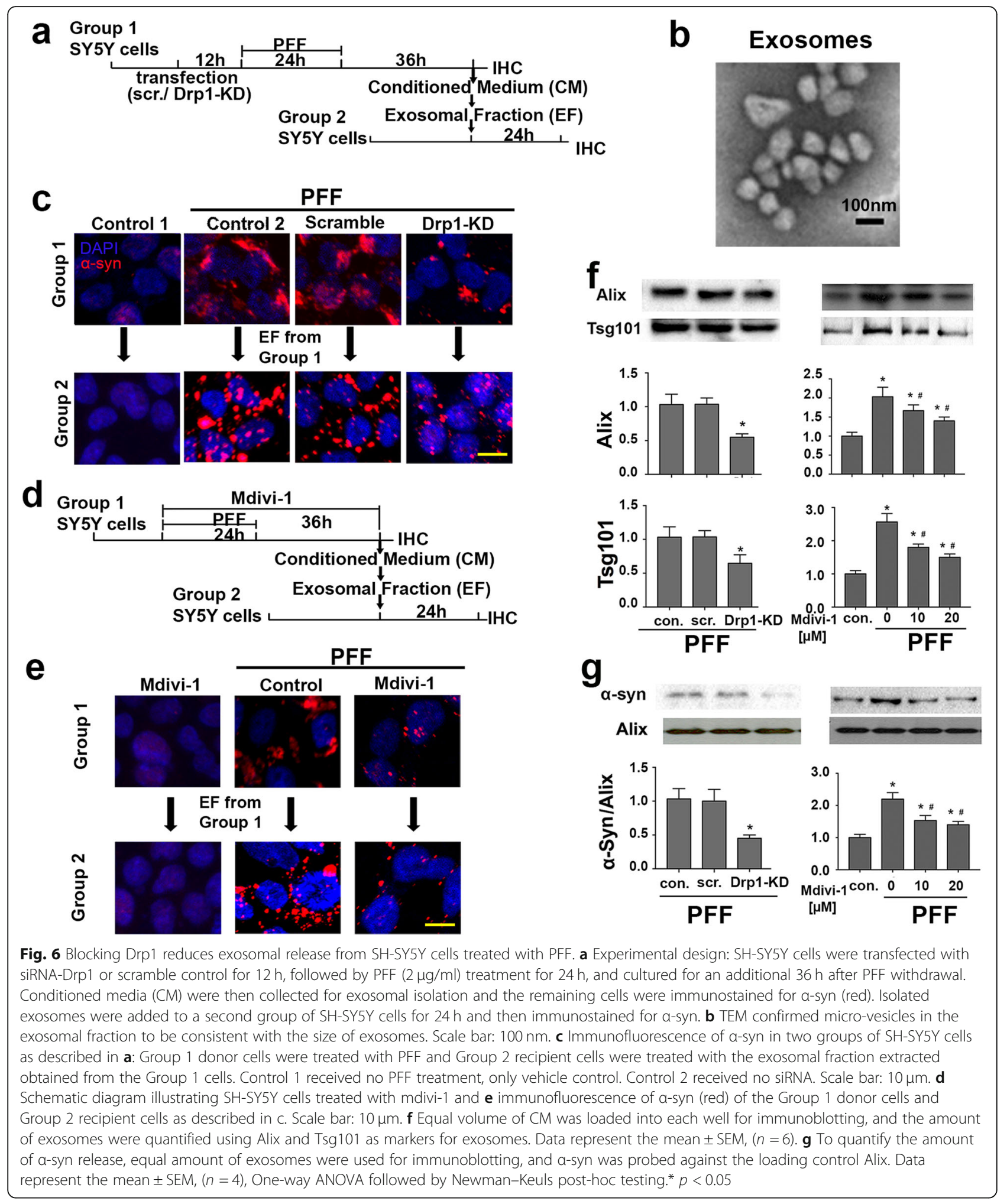

approach is to understand the impact of mitochondrial fusion and fission, not only for PD but also other neurodegenerative diseases $[2,31,66]$. It is now recognized that a balance in mitochondrial fusion and fission is critical to neuronal function and viability. Mitochondrial fusion requires the coordination of both the inner (IMM) and the outer (OMM) mitochondrial membranes. The OMM proteins Mitofusin 1 \& $2(\mathrm{Mfn} 1 / 2)$ 


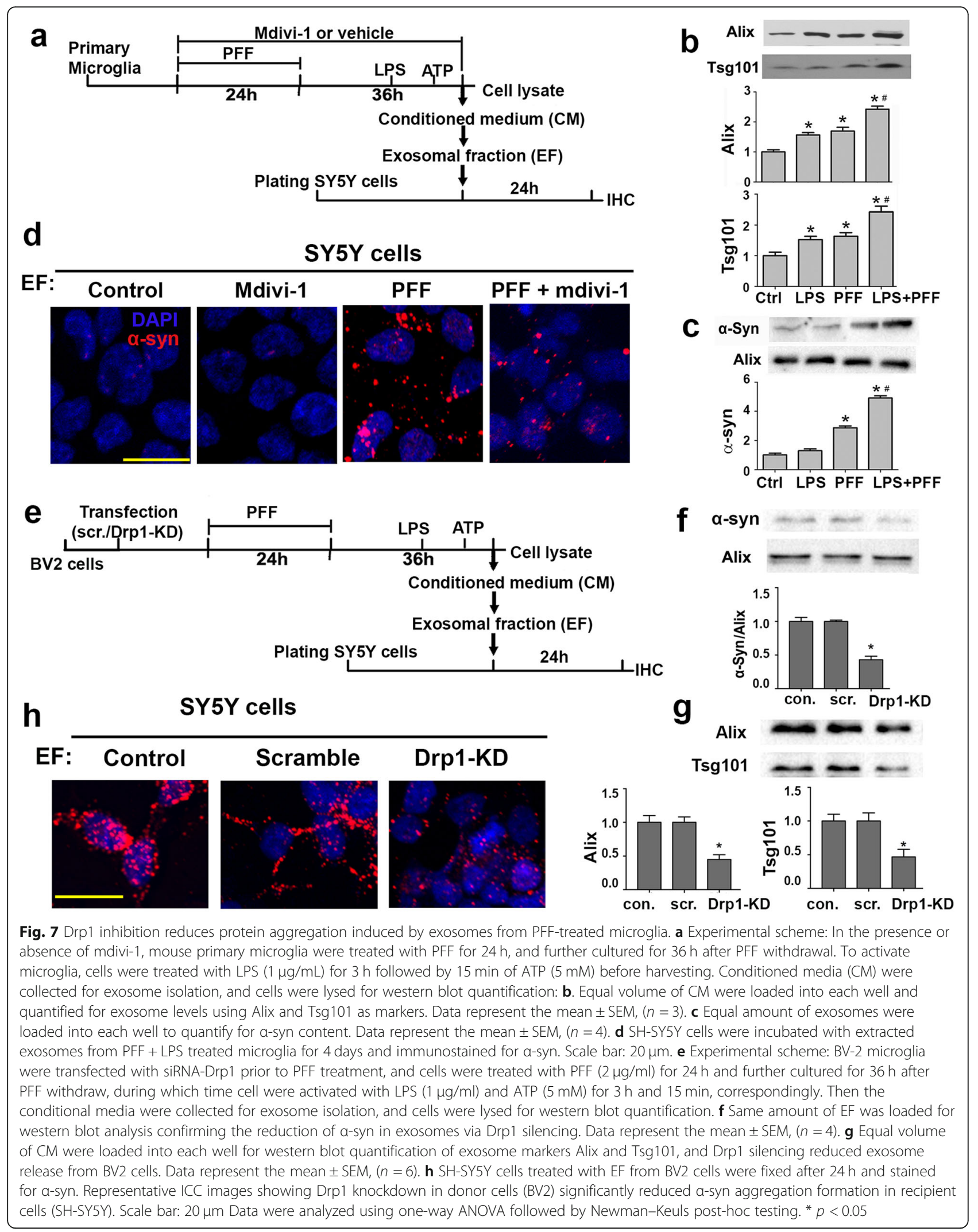


coordinate with the IMM Optic Atrophy-1 (Opa1) to join the membrane. Mitochondrial fission is governed by a separate set of proteins: Mitochondrial Fission Factor (Mff), Fission-1 (Fis1), as well as Mitochondrial Dynamics Proteins of 49 and $51 \mathrm{kDa}$ (MiD49 and MiD51, respectively) are anchored to the OMM where they recruit cytosolic Dynamin-related protein-1 (Drp1), which then oligomerizes and forms a ring-like structure around the mitochondria to constrict and split them [36, 49]. Because Drp1 can bind to multiple downstream fission proteins to sever mitochondria, it has earned the reputation as a master regulator of mitochondrial fission. However, as demonstrated in the present study, in addition to this well-established function, Drp1 has a novel role in autophagy.

Autophagy plays a critical role in removing misfolded proteins, including $\alpha$-syn $[14,37,67]$. Therefore, impairment in autophagy leads to accumulation of $\alpha$-syn, which further exacerbating the blockade of autophagy as demonstrated cell culture and animal models [4, 11, 19, 68, 72], thus creating a bidirectional positive feedback loop of neurotoxicity [70]. Strikingly, recent data from other laboratories and ours show that blocking Drp1 is capable of reducing protein aggregation. Reddy and colleagues, for example, reported than crossing $D r p 1^{+/-}$mice with either the A $\beta P P$ (Tg2576) or the Tau P301L transgenic mouse models of $(\mathrm{AD})$ reduced accumulation of toxic proteins in these animals [30, 41]. We recently demonstrated that pharmacological blocking of Drp1 dramatically reduced $\alpha$ syn aggregates in nigral DA neurons of rats overexpressing $\alpha$-synclein-A53T [4]. Together, these results suggest that one possible mechanism by which blocking Drp1 reduces protein aggregation is through an improvement in autophagic function.

Given the well-established function of Drp1 in mitochondrial fission and its potential role in autophagy, the present study evaluated the protective effects of Drp1 inhibition mediated through these two mechanisms. Using primarily genetic approaches to inhibit Drp1, we report here that reduced Drp1 function conferred protection against $\alpha$-syn induced impairment in both mitochondria and autophagy. In stable dopaminergic neuronal cells with inducible expression of $\alpha$-syn, reducing Drp1 function genetically (Drp1 knockdown and overexpression of Drp1-dominant negative) and pharmacologically (mdivi-1 treatment) attenuated the negative impacts of $\alpha$-syn on mitochondrial morphology and function (membrane potential, reactive oxygen species, respiration and spare respiratory capacity (SRC). A reduction in SRC leads to energy crisis when energy demand exceeds the supply ability of mitochondria. Indeed, SRC has been considered as a major factor that defines the survival of the neuron [13]. Importantly, Drp1 inhibition drastically reduced proteinase $\mathrm{K}$-resistant $\alpha$-syn aggregates as demonstrated using complementary approaches of reducing Drp1 function in multiple cell models with overexpressing human wild-type $\alpha$-syn or the treatment of recombinant $\alpha$-syn (PFF). Consistent with these observations of protein clearance, we demonstrated that Drp1 inhibition abolished autophagic impairment induced by $\alpha$-syn in multiple cell models. Furthermore, we assessed mTOR activity by quantifying the levels of its substrate, phosphor-4E-BP1, using immunoblotting of N27 cells overexpressing $\alpha$-syn with siRNA-Drp1 or scramble control. These results demonstrate that reducing Drp1 function blocks mTOR activity and thereby increasing autophagy flux. In combination, our data indicate that that Drp1 inhibition confers protection against $\alpha$-syn by both improving mitochondrial function and autophagy flux.

Blockade of the mitochondrial electron transport chain and autophagy flux has been shown to induce the spread of $\alpha$-syn inter-cellularly. For example, exposure of enteric neurons to rotenone, a mitochondrial complex I inhibitor, promotes the release of $\alpha$-syn, which is subsequently taken up by and form aggregates in the recipient neurons [47]. Emerging evidence indicates that $\alpha$-syn can spread intercellularly through exosome release, primarily because of its ability to impair mitochondria and autophagy $[1,25]$. Exosomes are small extracellular vesicles with a typical size of $40-100 \mathrm{~nm}$. Because these vesicles carry cargos such as mRNA and proteins, they could play a role in the spread of misfolded proteins such as $\alpha$-syn [12]. It has been demonstrated that impaired autophagy induces exosome-mediated $\alpha$-syn spread to other neurons [1], forming aggregates and inducing death in the receiving cell $[18,27]$. As demonstrated in this study, in addition to neurons, microglia are capable of releasing exosomes. Our data also indicate that when activated by LPS, microglia release drastically more exosomes. The role of activated microglia in causing neuroinflammation by releasing molecules such as TNF- $\alpha$, IL- $1 \beta$ and IL- 6 has been welldocumented and proposed to be involved in PD pathogenesis. Relevant to this study, LPS has been reported to induce mitochondrial fission in microglia leading to neuroinflammation. Using primary microglia [45] and the BV2 murine microglial cells [48], two independent studies show that LPS induces mitochondrial fragmentation and neuroinflammation via a Drp1-dependent mechanism. Blocking Drp1 using shDrp1 and mdivi-1 reduces LPSinduced release of pro-inflammatory molecules. In addition to microglia, astrocytes are capable of causing neuroinflammation [58] - although to a lesser extent than microglia. In primary mouse astrocytes and the human U373 astrocytes, manganese $(\mathrm{Mn})$ reduces oxidative phosphorylation, increases mitochondrial fragmentation and neuroinflammation - especially in the presence of supplemented aggregated $\alpha$-syn [58]. The mitochondrial targeted antioxidant mito-apocynin was demonstrated to be highly 
protective against $\mathrm{Mn}$-induced such alterations in astrocytes [58], suggesting impaired mitochondria as the cause of neuroinflammation. Together, these studies indicate that enhanced mitochondrial fission in microglia and astrocytes are linked to their production of proinflammatory molecules. It is most likely that the reduction of exosome release observed in this study was mediated through mechanisms related to improved mitochondrial function, reduced neuroinflammation and improved autophagy when Drp1 was inhibited.

\section{Conclusions}

Mitochondrial dysfunction, impaired autophagy flux, oxidative stress and $\alpha$-syn pathology (aggregation and spread) have all been proposed to play a dominant pathogenic role in PD. Blocking Drp1 function as a potential therapeutic strategy has gained interest in recent years for neurodegenerative diseases. We have reported that blocking Drp1 is neuroprotective in cell [15] and animal models of PD $[4,56]$. A complementary approach using a peptide known as P110 to block the binding of Drp1 to Fis1 has also been shown to be protective in the MPTP models [20, 54]. However, all these previous studies focused on the mitochondrial fission pathway. Using models of $\alpha$-syn, which is relevant to familial and sporadic PD, the present study provides the following novel observations: First, in addition to improving mitochondrial morphology and function, blocking Drp1 improved autophagy flux. Second, Drp1 inhibition reduced protein aggregation and spread from one cell to another via exosomes and non-cell autonomous mechanism. Together, these discoveries highlight new insights that Drp1 inhibition confers neuroprotection through both mitochondrial and autophagy-lysosomal pathways, further strengthening the therapeutic potential of targeting Drp1. The discovery that blocking Drp1 in microglia confers protection in neurons suggest that Drp1 should also be considered to be reduced in glial cells, not just in the affected neuronal population.

\section{Supplementary information}

Supplementary information accompanies this paper at https://doi.org/10. 1186/s40478-019-0821-4.

\footnotetext{
Additional file 1. Figure S1. Expression of tyrosine hydroxylase in N27 cells. Figure S2. Comparison of GFP signal in HeLa cells with or without PFA fixation. Figure S3. Generation of inducible expression of human asynuclein in rat dopaminergic N27 neuronal cells. Figure S4. Efficiency of Drp1 siRNA. Figure S5 Drp1 inhibition attenuates p62 accumulation in N27 neuronal cells with inducible a-syn. Figure S6 Morphology of PFF. Table S1. Primary antibodies and dilutions used in western blot. Table S2. Primary antibodies and dilutions used in immunostaining.
}

\section{Acknowledgements}

We thank Dr. Tan Li (Department of Biostatistics, Florida International University) for his advices on statistical analysis. Dr. Jeremy Chambers for proofreading this manuscript and constructive comments.

\section{Authors' contributions}

Conceived and designed the experiments: KT, MC, RF, MG, SL. Performed the experiments: RF, MG. Analyzed the data: KT, MC, RF, MG. Contributed reagents/ materials: SL provided the HeLa autophagy reporter cells. All authors read and approved the final manuscript.

\section{Funding}

This work was supported in part by the National Institute of Environmental Health Services (R01-ES022274 and R35-ES030523, KT), Medical Research Council UK (MR/L022079/1, KT), Robert Stempel College of Public Health \& Social Work, Florida International University and Peninsula Schools of Medicine and Dentistry (KT,RF, MG), Plymouth University, Plymouth, UK (RF).

\section{Availability of data and materials}

All data generated or analysed during this study are included in this published article and its supplementary information files.

\section{Ethics approval and consent to participate}

Not applicable.

\section{Consent for publication}

All authors have read the manuscript and accepted responsibility for the manuscript's content. The authors confirmed there are no conflicts of interest.

\section{Competing interests}

The authors declare that they have no competing interests.

\section{Author details}

${ }^{1}$ Department of Environmental Health Sciences, Florida International University, Miami, USA. ${ }^{2}$ Peninsula Schools of Medicine and Dentistry, Plymouth University, Plymouth, UK. ${ }^{3}$ Department of Neurology, Huashan hospital, Fudan University, Shanghai, China.

Received: 12 August 2019 Accepted: 29 September 2019 Published online: 19 November 2019

\section{References}

1. Alvarez-Erviti L, Seow Y, Schapira AH, Gardiner C, Sargent IL, Wood MJ, Cooper JM (2011) Lysosomal dysfunction increases exosome-mediated alpha-synuclein release and transmission. Neurobiol Dis 42:360-367

2. Andreux PA, Houtkooper RH, Auwerx J (2013) Pharmacological approaches to restore mitochondrial function. Nat Rev Drug Discov 12:465-483

3. Appel-Cresswell S, Vilarino-Guell C, Encarnacion M, Sherman H, Yu I, Shah B, Weir D, Thompson C, Szu-Tu C, Trinh J et al (2013) Alpha-synuclein p.H50Q, a novel pathogenic mutation for Parkinson's disease. Mov Disord 28:811813

4. Bido S, Soria FN, Fan RZ, Bezard E, Tieu K (2017) Mitochondrial division inhibitor-1 is neuroprotective in the A53T-alpha-synuclein rat model of Parkinson's disease. Sci Rep 7:7495. https://doi.org/10.1038/s41598-01707181-0

5. Bjorkoy G, Lamark T, Brech A, Outzen H, Perander M, Overvatn A, Stenmark H, Johansen T (2005) p62/SQSTM1 forms protein aggregates degraded by autophagy and has a protective effect on huntingtin-induced cell death. J Cell Biol 171:603-614. https://doi.org/10.1083/jcb.200507002

6. Bordt EA, Clerc P, Roelofs BA, Saladino AJ, Tretter L, Adam-Vizi V, Cherok E, Khalil A, Yadava N, Ge SX et al (2017) The putative Drp1 inhibitor mdivi-1 is a reversible mitochondrial complex I inhibitor that modulates reactive oxygen species. Dev Cell 40:583-594

7. Bourdenx M, Dovero S, Engeln M, Bido S, Bastide MF, Dutheil N, Vollenweider I, Baud L, Piron C, Grouthier V et al (2015) Lack of additive role of ageing in nigrostriatal neurodegeneration triggered by alpha-synuclein overexpression. Acta Neuropathol Commun 3:46. https://doi.org/10.1186/ s40478-015-0222-2 46-0222

8. Button RW, Lin F, Ercolano E, Vincent JH, Hu B, Hanemann CO, Luo S (2014) Artesunate induces necrotic cell death in schwannoma cells. Cell Death Dis 5:e1466. https://doi.org/10.1038/cddis.2014.434

9. Button RW, Roberts SL, Willis TL, Hanemann CO, Luo S (2017) Accumulation of autophagosomes confers cytotoxicity. J Biol Chem 292:13599-13614. https://doi.org/10.1074/jbc. M117.782276 
10. Button RW, Vincent JH, Strang CJ, Luo S (2016) Dual PI-3 kinase/mTOR inhibition impairs autophagy flux and induces cell death independent of apoptosis and necroptosis. Oncotarget 7:5157-5175. https://doi.org/10. 18632/oncotarget.6986

11. Chen L, Xie Z, Turkson S, Zhuang X (2015) A53T human alpha-synuclein overexpression in transgenic mice induces pervasive mitochondria macroautophagy defects preceding dopamine neuron degeneration. J Neurosci 35:890-905. https://doi.org/10.1523/jneurosci.0089-14.2015

12. Chistiakov DA, Chistiakov AA (2017) Alpha-Synuclein-carrying extracellular vesicles in Parkinson's disease: deadly transmitters. Acta Neurol Belg 117:43-51

13. Choi SW, Gerencser AA, Nicholls DG (2009) Bioenergetic analysis of isolated cerebrocortical nerve terminals on a microgram scale: spare respiratory capacity and stochastic mitochondrial failure. J Neurochem 109:1179-1191

14. Cuervo AM, Stefanis L, Fredenburg R, Lansbury PT, Sulzer D (2004) Impaired degradation of mutant alpha-synuclein by chaperone-mediated autophagy. Science 305:1292-1295. https://doi.org/10.1126/science.1101738

15. Cui M, Tang X, Christian W, Yoon Y, Tieu K (2010) Perturbations in mitochondrial dynamics induced by human mutant PINK1 can be rescued by the mitochondrial division inhibitor mdivi-1. J Biol Chem 285:11740-11752

16. Decressac M, Mattsson B, Lundblad M, Weikop P, Bjorklund A (2012) Progressive neurodegenerative and behavioural changes induced by AAVmediated overexpression of alpha-synuclein in midbrain dopamine neurons. Neurobiol Dis 45:939-953

17. Dehay B, Bourdenx M, Gorry P, Przedborski S, Vila M, Hunot S, Singleton A, Olanow CW, Merchant KM, Bezard E et al (2015) Targeting alpha-synuclein for treatment of Parkinson's disease: mechanistic and therapeutic considerations. Lancet Neurol 14:855-866

18. Desplats P, Lee HJ, Bae EJ, Patrick C, Rockenstein E, Crews L, Spencer B, Masliah E, Lee SJ (2009) Inclusion formation and neuronal cell death through neuron-to-neuron transmission of alpha-synuclein. Proc Natl Acad Sci U S A 106:13010-13015

19. Ebrahimi-Fakhari D, Cantuti-Castelvetri I, Fan Z, Rockenstein E, Masliah E, Hyman BT, McLean PJ, Unni VK (2011) Distinct roles in vivo for the ubiquitin-proteasome system and the autophagy-lysosomal pathway in the degradation of a-synuclein. J Neurosci 31:14508-14520. https:/doi.org/10.1523/jneurosci.1560-11.2011

20. Filichia E, Hoffer B, Qi X, Luo Y (2016) Inhibition of Drp1 mitochondrial translocation provides neural protection in dopaminergic system in a Parkinson's disease model induced by MPTP. Sci Rep, City, p 32656

21. Floden AM, Combs CK (2006) Beta-amyloid stimulates murine postnatal and adult microglia cultures in a unique manner. J Neurosci 26:4644-4648. https://doi.org/10.1523/jneurosci.4822-05.2006

22. Franco-Iborra S, Vila M, Perier C (2016) The Parkinson disease mitochondrial hypothesis: where are we at? Neuroscientist 22:266-277

23. Freeman D, Cedillos R, Choyke S, Lukic Z, McGuire K, Marvin S, Burrage AM, Sudholt S, Rana A, O'Connor C et al (2013) Alpha-synuclein induces lysosoma rupture and cathepsin dependent reactive oxygen species following endocytosis. PLoS One 8:e62143. https://doi.org/10.1371/journal.pone.0062143

24. Freundt EC, Maynard N, Clancy EK, Roy S, Bousset L, Sourigues Y, Covert M, Melki R, Kirkegaard K, Brahic M (2012) Neuron-to-neuron transmission of alpha-synuclein fibrils through axonal transport. Ann Neurol 72:517-524

25. Guo JL, Lee VM (2014) Cell-to-cell transmission of pathogenic proteins in neurodegenerative diseases. Nat Med 20:130-138. https://doi.org/10.1038/ nm.3457

26. Hamza TH, Zabetian CP, Tenesa A, Laederach A, Montimurro J, Yearout D, Kay DM, Doheny KF, Paschall J, Pugh E et al (2010) Common genetic variation in the HLA region is associated with late-onset sporadic Parkinson's disease. Nat Genet 42:781-785

27. Hansen C, Angot E, Bergstrom AL, Steiner JA, Pieri L, Paul G, Outeiro TF, Melki R, Kallunki P, Fog K et al (2011) Alpha-Synuclein propagates from mouse brain to grafted dopaminergic neurons and seeds aggregation in cultured human cells. J Clin Invest 121:715-725

28. Helley MP, Pinnell J, Sportelli C, Tieu K (2017) Mitochondria: a common target for genetic mutations and environmental toxicants in Parkinson's disease. Front Genet 8:177. https://doi.org/10.3389/fgene.2017.00177

29. Hernandez DG, Reed X, Singleton AB (2016) Genetics in Parkinson disease: Mendelian versus non-Mendelian inheritance. J Neurochem 139(Suppl 1): 59-74. https://doi.org/10.1111/jnc.13593

30. Kandimalla R, Manczak M, Fry D, Suneetha Y, Sesaki H, Reddy PH (2016) Reduced Dynamin-related protein 1 protects against phosphorylated tauinduced mitochondrial dysfunction and synaptic damage in Alzheimer's disease. Hum Mol Genet, 2016;25(22):4881-4897
31. Kandimalla R, Reddy PH (2016) Multiple faces of dynamin-related protein 1 and its role in Alzheimer's disease pathogenesis. Biochim Biophys Acta 1862:814-828. https://doi.org/10.1016/j.bbadis.2015.12.018

32. Kimura S, Noda T, Yoshimori T (2007) Dissection of the autophagosome maturation process by a novel reporter protein, tandem fluorescent-tagged LC3. Autophagy 3:452-460

33. Klionsky DJ (2005) The molecular machinery of autophagy: unanswered questions. J Cell Sci 118:7-18. https://doi.org/10.1242/jcs.01620

34. Kruger R, Kuhn W, Muller T, Woitalla D, Graeber M, Kosel S, Pzuntek H, Epplen JT, Schols L, Riess O (1998) Ala30Pro mutation in the gene encoding alpha-synuclein in Parkinson's disease. Nat Genet 18:107-108

35. Langston JW, Ballard P, Irwin I (1983) Chronic parkinsonism in humans due to a product of meperidine-analog synthesis. Science 219:979-980

36. Lee H, Yoon Y (2016) Mitochondrial fission and fusion. Biochem Soc Trans 44:1725-1735. https://doi.org/10.1042/bst20160129

37. Lee HJ, Khoshaghideh F, Patel S, Lee SJ (2004) Clearance of alpha-synuclein oligomeric intermediates via the lysosomal degradation pathway. J Neurosc 24:1888-1896. https://doi.org/10.1523/jneurosci.3809-03.2004

38. Lesage $S$, Anheim $M$, Letournel F, Bousset L, Honore A, Rozas N, Pieri L, Madiona K, Durr A, Melki R et al (2013) G51D alpha-synuclein mutation causes a novel parkinsonian-pyramidal syndrome. Ann Neurol 73:459-471

39. Lill CM, Roehr JT, McQueen MB, Kavvoura FK, Bagade S, Schjeide BM, Schjeide LM, Meissner E, Zauft U, Allen NC et al (2012) Comprehensive research synopsis and systematic meta-analyses in Parkinson's disease genetics: the PDGene database. PLoS Genet 8:e1002548. 1002510.1001371/ journal.pgen.1002548. https://doi.org/10.1371/journal.pgen.1002548

40. Luk KC, Kehm VM, Zhang B, O'Brien P, Trojanowski JQ, Lee VM (2012) Intracerebral inoculation of pathological alpha-synuclein initiates a rapidly progressive neurodegenerative alpha-synucleinopathy in mice. J Exp Med 209:975-986

41. Manczak M, Kandimalla R, Fry D, Sesaki H, Reddy PH (2016) Protective effects of reduced dynamin-related protein 1 against amyloid beta-induced mitochondrial dysfunction and synaptic damage in Alzheimer's disease. Hum Mol Genet, 2016:25(23):5148-5166

42. Manczak M, Kandimalla R, Yin X, Reddy PH (2019) Mitochondrial division inhibitor 1 reduces dynamin-related protein 1 and mitochondrial fission activity. Hum Mol Genet 28:177-199. https://doi.org/10.1093/hmg/ddy335

43. Martin P, Albagli O, Poggi MC, Boulukos KE, Pognonec P (2006) Development of a new bicistronic retroviral vector with strong IRES activity. BMC biotechnology. 6:4. https://doi.org/10.1186/1472-6750-6-4

44. Mookerjee SA, Gerencser AA, Nicholls DG, Brand MD (2017) Quantifying intracellular rates of glycolytic and oxidative ATP production and consumption using extracellular flux measurements. J Biol Chem 292:71897207. https://doi.org/10.1074/jbc. M116.774471

45. Nair S, Sobotka KS, Joshi P, Gressens P, Fleiss B, Thornton C, Mallard C, Hagberg H (2019) Lipopolysaccharide-induced alteration of mitochondrial morphology induces a metabolic shift in microglia modulating the inflammatory response in vitro and in vivo. Glia 67:1047-1061. https://doi. org/10.1002/glia.23587

46. Nalls MA, Pankratz N, Lill CM, Do CB, Hernandez DG, Saad M, DeStefano AL, Kara E, Bras J, Sharma M et al (2014) Large-scale meta-analysis of genomewide association data identifies six new risk loci for Parkinson's disease. Nat Genet 2014(07/27):989-993. https://doi.org/10.1038/ng.3043

47. Pan-Montojo F, Schwarz M, Winkler C, Arnhold M, O'Sullivan GA, Pal A, Said J, Marsico G, Verbavatz JM, Rodrigo-Angulo M et al (2012) Environmental toxins trigger PD-like progression via increased alpha-synuclein release from enteric neurons in mice. Sci Rep 2:898. https://doi.org/10.1038/srep00898

48. Park J, Choi H, Min JS, Park SJ, Kim JH, Park HJ, Kim B, Chae J, Yim M, Lee DS (2013) Mitochondrial dynamics modulate the expression of proinflammatory mediators in microglial cells. J Neurochem 127:221-232. https://doi.org/10.1111/jnc.12361

49. Pernas L, Scorrano L (2016) Mito-Morphosis: mitochondrial fusion, fission, and cristae remodeling as key mediators of cellular function. Annu Rev Physiol 78:505-531. https://doi.org/10.1146/annurev-physiol-021115-105011

50. Polymeropoulos MH, Lavedan C, Leroy E, Ide SE, Dehejia A, Dutra A, Pike B, Root H, Rubenstein J, Boyer R et al (1997) Mutation in the alpha-synuclein gene identified in families with Parkinson's disease. Science 276:2045-2047

51. Prasad KN, Carvalho E, Kentroti S, Edwards-Prasad J, Freed C, Vernadakis A (1994) Establishment and characterization of immortalized clonal cell lines from fetal rat mesencephalic tissue. In Vitro Cell Dev Biol Anim 30A:596-603. 
52. Prasad KN, Clarkson ED, La Rosa FG, Edwards-Prasad J, Freed CR (1998) Efficacy of grafted immortalized dopamine neurons in an animal model of parkinsonism: a review. Mol Genet Metab 65:1-9.

53. Przedborski S (2017) The two-century journey of Parkinson disease research. Nat Rev Neurosci 18:251-259

54. Qi X, Qvit N, Su YC, Mochly-Rosen D (2013) A novel Drp1 inhibitor diminishes aberrant mitochondrial fission and neurotoxicity. J Cell Sci 126: 789-802

55. Rappold PM, Cui M, Chesser AS, Tibbett J, Grima JC, Duan L, Sen N, Javitch JA, Tieu K (2011) Paraquat neurotoxicity is mediated by the dopamine transporter and organic cation transporter-3. Proc Natl Acad Sci U S A 108: 20766-20771

56. Rappold PM, Cui M, Grima JC, Fan RZ, de Mesy-Bentley KL, Chen L, Zhuang X, Bowers WJ, Tieu K (2014) Drp1 inhibition attenuates neurotoxicity and dopamine release deficits in vivo. Nat Commun 5:5244. https://doi.org/10. 1038/ncomms6244

57. Ravikumar B, Vacher C, Berger Z, Davies JE, Luo S, Oroz LG, Scaravilli F, Easton DF, Duden R, O'Kane CJ et al (2004) Inhibition of mTOR induces autophagy and reduces toxicity of polyglutamine expansions in fly and mouse models of Huntington disease. Nat Genet 36:585-595. https://doi. org/10.1038/ng1362

58. Sarkar S, Malovic E, Harischandra DS, Ngwa HA, Ghosh A, Hogan C, Rokad D, Zenitsky G, Jin H, Anantharam V et al (2018) Manganese exposure induces neuroinflammation by impairing mitochondrial dynamics in astrocytes. Neurotoxicology 64:204-218. https://doi.org/10.1016/j.neuro.2017.05.009

59. Satake W, Nakabayashi Y, Mizuta I, Hirota Y, Ito C, Kubo M, Kawaguchi T, Tsunoda T, Watanabe M, Takeda A et al (2009) Genome-wide association study identifies common variants at four loci as genetic risk factors for Parkinson's disease. Nat Genet 41:1303-1307

60. Simonsen A, Tooze SA (2009) Coordination of membrane events during autophagy by multiple class III PI3-kinase complexes. J Cell Biol 186:773782. https://doi.org/10.1083/jcb.200907014

61. Singleton AB, Farrer M, Johnson J, Singleton A, Hague S, Kachergus J, Hulihan M, Peuralinna T, Dutra A, Nussbaum R et al (2003) Alpha-Synuclein locus triplication causes Parkinson's disease. Science 302:841

62. Smirnova E, Griparic L, Shurland DL, van der Bliek AM (2001) Dynaminrelated protein Drp1 is required for mitochondrial division in mammalian cells. Mol Biol Cell 12:2245-2256

63. Smith G, Gallo G (2017) To mdivi-1 or not to mdivi-1: is that the question? Dev Neurobiol 77:1260-1268

64. Spillantini MG, Crowther RA, Jakes R, Hasegawa M, Goedert M (1998) Asynuclein in filamentous inclusions of Lewy bodies from Parkinson's disease and dementia with Lewy bodies. Proc Natl Acad Sci U S A 95:6469-6473

65. Volpicelli-Daley LA, Luk KC, Lee VM (2014) Addition of exogenous alphasynuclein preformed fibrils to primary neuronal cultures to seed recruitment of endogenous alpha-synuclein to Lewy body and Lewy neurite-like aggregates. Nat Protoc 9:2135-2146

66. Wang W, Karamanlidis G, Tian R (2016) Novel targets for mitochondrial medicine. Sci Transl Med 8:326rv323

67. Webb JL, Ravikumar B, Atkins J, Skepper JN, Rubinsztein DC (2003) AlphaSynuclein is degraded by both autophagy and the proteasome. J Biol Chem 278:25009-25013. https://doi.org/10.1074/jbc. M300227200

68. Winslow AR, Chen CW, Corrochano S, Acevedo-Arozena A, Gordon DE, Peden AA, Lichtenberg M, Menzies FM, Ravikumar B, Imarisio S et al (2010) Alpha-Synuclein impairs macroautophagy: implications for Parkinson's disease. J Cell Biol 190:1023-1037. https://doi.org/10.1083/jcb.201003122

69. Wu M, Neilson A, Swift AL, Moran R, Tamagnine J, Parslow D, Armistead S, Lemire K, Orrell J, Teich J et al (2007) Multiparameter metabolic analysis reveals a close link between attenuated mitochondrial bioenergetic function and enhanced glycolysis dependency in human tumor cells. Am J Physiol Cell Physiol 292:C125-C136. https://doi.org/10.1152/ajpcell.00247.2006

70. Xilouri M, Brekk OR, Stefanis L (2016) Autophagy and alpha-Synuclein: relevance to Parkinson's disease and related Synucleopathies. Mov Disord 31:178-192. https://doi.org/10.1002/mds.26477

71. Xu J, Camfield R, Gorski SM (2018) The interplay between exosomes and autophagy - partners in crime. J Cell Sci 131:jcs215210. https://doi.org/10. $1242 / j c s .215210$

72. Yu WH, Dorado B, Figueroa HY, Wang L, Planel E, Cookson MR, Clark LN, Duff KE (2009) Metabolic activity determines efficacy of macroautophagic clearance of pathological oligomeric alpha-synuclein. Am J Pathol 175:736747. https://doi.org/10.2353/ajpath.2009.080928
73. Zarranz JJ, Alegre J, Gomez-Esteban JC, Lezcano E, Ros R, Ampuero I, Vidal L, Hoenicka J, Rodriguez O, Atares B et al (2004) The new mutation, E46K, of alpha-synuclein causes Parkinson and Lewy body dementia. Ann Neurol 55: 164-173

\section{Publisher's Note}

Springer Nature remains neutral with regard to jurisdictional claims in published maps and institutional affiliations.
Ready to submit your research? Choose BMC and benefit from:

- fast, convenient online submission

- thorough peer review by experienced researchers in your field

- rapid publication on acceptance

- support for research data, including large and complex data types

- gold Open Access which fosters wider collaboration and increased citations

- maximum visibility for your research: over $100 \mathrm{M}$ website views per year

At $\mathrm{BMC}$, research is always in progress.

Learn more biomedcentral.com/submissions 